\title{
Strategies to stabilize cell penetrating peptides for in vivo application
}

\author{
Jesús Fominaya ${ }^{1}$, Jerónimo Bravo² \& Angelita Rebollo*,1 \\ ${ }^{1}$ CIMI-Paris, UPMC, Inserm 1135, Hôpital Pitie S alpêtrière, Paris, France \\ ${ }^{2}$ Ins tituto de Biomedicina de Valencia, CSIC, Valencia, S pain \\ *Author for correspondence: Tel.: +33 140778109; Fax: +33 \\ 145838858; angelita.rebollo@ upmc.fr
}

\begin{abstract}
In the era of biomedicines and engineered carrier systems, cell penetrating peptides (CPPS) have been established as a promising tool for therapeutic application. Likewise, other therapeutic peptides, successful in vivo application of CPPs will strongly depend on peptide stability, the bottleneck for this type of biodegradable molecules. In this review, the authors describe the current knowledge of the in vivo degradation for known CPPs and the different strategies available to provide a higher resistance to metabolic degradation while preserving cell penetration efficiency. Peptide stability can be improved by different means, either modifying the structure to make it unrecognizable to proteases, or preventing access of proteolytic enzymes by applying conformation restriction or shielding strategies.
\end{abstract}




\section{Key terms}

Bio-barrier: Natural defensive boundary that preserves the organism from entrance of dangerous elements.

Cell-

penetrating peptide:

A short peptide (5-30 amino acids) with the ability to cross cell membranes acting as a carrier to facilitate cellular uptake of membrane-impermeable molecules.

Biological modification of CPPs:

Any alteration of the CPP original sequence that maintains the natural peptide character and keeps the final structure potentially biodegradable.

Chemical Change of the natural CPP structure by nonbiological means. It includes unnatural modification of structures or modifications that only appear in nature under very restricted CPPs: $\quad$ circumstances (D-amino acids, cyclization).

Conformational Limitation of the natural conformational flexibility leading to higher rigidity and constraint: reducing protease accessibility.

To perform its therapeutic function, a drug has to pass through different biological barriers before reaching its target. Success will depend on the administration route (the number of bio-barriers it must go through), the formulation (presence of additives, stabilizers, etc.) and the intrinsic characteristics of the molecule (size, solubility, hydrophobicity, stability, etc.). If the final target is a molecule within a cell, there is a common barrier to overcome the cell membrane. This is not a real challenge for small hydrophobic molecules than can passively diffuse through it. However, plasma membrane is almost impermeable to hydrophilic molecules and most structures above a certain molecular weight. But nature has developed different strategies to overcome this limitation and gain access to the cell, from shuttle proteins to parasite microorganisms, such as viruses. In most cases, there are specific sequences within particular proteins that are responsible for the translocation function. Some of these sequences have been mapped and further demonstrated their ability to cross cell membranes when used as isolated peptides. This was the origin of the so-called 'cell penetrating peptides' (CPPs) that were defined in the mid-1990s after the discovery of Tat peptide, derived from the TransActivator of Transcription protein of human immunodeficiency virus [1] and pAnt (43-58), further known as penetratin, derived from the third helix of the Antennapedia homeodomain protein [2]. Since then, CPPs have demonstrated to be efficient shuttles for introducing different kind of cargoes within a great variety of cells, both in vitro and in vivo [3-7]. Cargoes range from small organic molecules to nanoparticles and liposomes, and include peptides, proteins, siRNAs, plasmid DNA and imaging agents. Some CPPs derive from natural sequences while others have been obtained by rational design, generating a great structural, chemical and functional diversity that increases the spectrum of possible applications [8]. Sequences with different sizes (5-30 residues), charge (cationic, anionic or neutral), polarity (hydrophobic, amphipathic or cationic), secondary structure ( $\alpha$-helical, $\beta$-sheet, $\beta$-turn, random coil) and amino acid composition (Arg-rich, Pro-rich) have been described, sharing all the ability to cross cell 
membranes [3]. This wide diversity results in a variety of mechanisms of cell uptake, with endocytosis and direct translocation through plasma membrane as the major modes of action [9]. In addition to CPP physical-chemical properties, other aspects governing internalization include cell type, plasma membrane composition and dynamic (lipid density and composition, presence of glycosaminoglycans, specific proteins), CPP concentration (above a concentration threshold cell uptake could change from endocytic route to direct translocation) and CPP/cell stoichiometry [10].

CPPs were soon considered a promising shuttle for in vivo applications, with special emphasis in their potential as imaging tools and therapy [11,12]. Therapeutic applications, some already in clinical development, include antimicrobial actions, anti-inflammatory effects, skin diseases, hearing loss, neuroprotection, cardioprotection, analgesia, vaccine development, gene therapy and cancer [13-16]. Applications are not necessarily restricted to medical aspects and have been extended to completely different applications such as agricultural pest control and plant engineering $[17,18]$. In vivo usage requires additional considerations different from the simpler and easily controlled in vitro research purposes. Before reaching the particular cell membrane to cross, CPPs have to go through different biological barriers depending on the administration route (intravenous injection, intramuscular, intraperitoneal, oral, local). Natural defensive bio-barriers include the skin, a diversity of mucosa (oral, nasal, pulmonary, ocular, otic, vaginal, rectal) and epithelial/endothelial cell barriers, such as the intestine wall or the blood-brain barrier (BBB). Examples of successful usage of CPPs that overcome these bio-barriers have been reported. Topical administration of CPP-driven therapeutic complexes has allowed transdermal drug delivery through the skin as well as mucosal delivery by ocular and nasal routes [19-24]. BBB is a highly selective filter that protects the brain from unwanted invaders resulting in a real challenge for the pharmacologic delivery of macromolecules. CPPs have also demonstrated their ability to transfer different payloads through this bio-barrier [25-27]. However, the main challenge for peptides, proteins and other biomolecules is the oral delivery, due to the highly aggressive acidic environment of the gastric milieu and the intensive proteolytic activity of the intestinal tract. This is the most convenient form to ensure treatment adherence, being the classical administration way for traditional drugs. The research community is expanding big efforts to achieve this goal. Fortunately, the development of modified stable CPPs appears as a promising option for oral delivery of biological payloads, showing excellent results both in vitro, in simulated gastric conditions [28], and in vivo, to either ensure a proper delivery of the associated cargo or to be used as excipient for oral delivery of traditional biological drugs that were not amenable to this administration route, such as insulin [29-31].

The major limitations of CPPs for in vivo applications are poor cell and tissue selectivity, low bioavailability and metabolic instability, while reduced immunogenicity or toxicity and rapid delivery of cargoes into cells appeared as clear advantages. Most CPPs have a net positive charge that allows 
them to bind to negatively charged cell membranes but they are not able to discriminate among cell types. A certain level of selectivity in pathological situations can be obtained for the highly positively charged CPPs. They will be particularly effective in penetrating membranes in the acidic areas associated with tumor development $[32,33]$. In addition, they can passively accumulate in specific pathological locations due to the enhanced permeability and retention (EPR) effect, a tropism based on the leaky vasculature occurring at damaged sites, such as tumors, infarcts or infection places [34]. Different strategies have been employed to provide target cell specificity, either by using homing peptides, identifying receptor-specific sequences, designing peptides with dual properties (cell selectivity and penetration capability) or applying controlled delivery strategies based on various stimuliresponsive mechanisms, either internal (presence of specific local proteases, lower $\mathrm{pH}$, higher temperature, hypoxia) or external (heat, radiofrequencies, magnetic fields), allowing a proper control by the therapist [4,35-37]. Even incorporating structures that facilitate target selectivity to CPPs, metabolic stability remains a major concern for in vivo applications. The interest of this topic is clear and justifies a more detailed analysis of the reasons for this apparent weakness, the possible mechanisms for peptide degradation and the current strategies that are being applied to increase CPP's stability, in vivo half-life and bioavailability. Some of those strategies can simultaneously improve peptide stability, together with other characteristics such as penetrability or specificity.

\section{In vivo peptide degradation}

Peptide stability in aqueous buffer solutions depends on intrinsic parameters (length, amino acid sequence, three-dimensional structure) and external physical and chemical variables ( $\mathrm{pH}$, temperature, concentration, ionic strength, presence of additives). Peptide functionality requires physical, chemical and metabolic integrity. Physical stability is associated to the ability to stay in solution in a functional manner (correct conformation) and may be affected by the peptide's tendency to get absorbed to surfaces and/or to induce aggregation states that can eventually reduce its solubility or activity. Chemical instability may occur by some nonenzymatic degradation and include mechanisms such as acid/base hydrolysis, deamidation (mainly affecting asparagine and glutamine), oxidation (affecting residues such as methionine, cysteine, histidine, tryptophan or tyrosine), disulfide exchange induced by $\beta$-elimination of cystine residues or isomerization, among others [38,39]. However, the real challenge for the use of peptide pharmaceuticals is their sensitivity to enzymatic degradation. Biological fluids are an aggressive environment for peptides due to the presence of proteases and peptidases. This is a serious drawback for their therapeutic application limiting circulation half-life and bioavailability. Enzymes capable of degrading peptides have been detected from the inner side of cells (cytosol, endosomes, lysosomes) to the extracellular milieu, both as soluble proteins and bound to biological 
membranes. They are particularly abundant in bio-barriers that act as body defense. Therefore, determination of metabolic stability of CPPs is a crucial feature to ensure a maximal yield for in vivo success.

One of the first detailed studies of in vitro stability was performed with pVEC, a CPP derived from murine vascular endothelial cadherin [40]. pVEC remained intact in phosphate buffer but was degraded when incubated in human serum or serum-containing media (in vitro study), rapidly losing its C-terminal Lys. However, the synthetic all-D analog of pVEC, with all natural L-amino acid residues replaced by the isomeric counterparts, was stable in serum and resisted enzymatic degradation when incubated with proteases such as trypsin or carboxypeptidase A and B. Interestingly, when unmodified pVEC stability was studied in cell culture, a major degradation product appeared in both the extra- and the intracellular media corresponding to the peptide lacking the C-terminal Lys. The presence of this limited proteolysis product indicated that structural features beyond the linear sequence may contribute to the overall stability even for a short peptide (18 residues) and was justified by the potential existence of aggregated pVEC where only the C-terminal residue was accessible to proteolytic degradation. The same group extended the study to other CPPs: transportan, its analog TP10 and penetratin [41]. They found differences in metabolic stability with a decreasing stability order: transportan > TP10 > penetratin. Similarly, they found a limited proteolytic fragment derived from transportan coinciding with a fragment of mastoparan (3-14), the C-terminal part of the parental peptide obtained as a fusion of 12 functional residues from the neuropeptide galanin and the wasp venom peptide toxin mastoparan [42].

A similar study was performed with a group of selected fluorescently labeled CPPs: human calcitonin (hCT) derived peptides, Tat and penetratin [43]. The authors incubated them with different epithelial cells in culture, simulating one of the first natural metabolic barriers, the epithelia. Peptide metabolism depended on the epithelial model but shared a common pattern of degradation. It started with an initial internal cleavage, possibly by some endopeptidase, dividing the peptide in two fragments that were further degraded by other proteolytic enzymes, probably exopeptidases, leading to complete degradation. This work was further extended to a new group of four oligocationic CPPs: carboxyfluorescein (CF) labeled Sweet Arrow Peptide (SAP), a branched modification of CF-hCT(9-32) and two members of the MPG family, $[\mathrm{Pa}]$ and $[\mathrm{P} \beta]$ [44]. Despite the higher metabolic stability of CFmodified peptides, specific cleavage sites were identified in all cases. Looking for this selective initial internal cleavage site driving the metabolic processing of CPPs, Peng et al. performed a biological degradation simulation study with penetratin using low-energy collision-induced dissociation condition in MS [45]. They found the initial cleavage site at the amide bond between lysine 15 and 16, just at the Cterminal position, with the main domain of the peptide backbone stabilized with an a-helical structure. Modification of the C-terminal residue (K16) by acylation reduced fragmentation at this position, but 
substitution of $\mathrm{K} 15$ and $\mathrm{K} 16$ with alanine simply moved the primary cleavage site from the C-terminal to the N-terminal (Q2-I3) site. Similarly, a metabolic study performed with Tat peptide manifested that the main initial fragmentation occurred at the C-terminal Arg residues, an area that was identified as a putative furin cleavage site $[46,47]$. In a recent study of serum stability of a CPP derived from casein kinase $2 \alpha[48,49]$, the primary cleavage site was located at position R8-E9. Substitution of this Arg residue by either Lys, Asn or Ala improved peptide stability and pharmacokinetic properties, without altering the penetration capability [50]. All these studies indicate that peptide degradation will follow a certain pattern (sequence/structure-specific) with critical labile points of higher accessibility to proteolytic enzymes as nucleation points to initiate the metabolic processing. Therefore, knowledge of these mechanisms and identification of the initial cleavage sites may provide useful information for further modification of CPPs in order to enhance metabolic stability and increase the likelihood that these new tools become efficient delivery systems for therapeutic applications.

The common biological barrier for all CPPs is the plasma membrane. Extracellular peptide degradation restricts CPP uptake efficiency. However, peptide stability within cell is not ensured and CPP will still be exposed to metabolic degradation. Once the intracellular cargo target site has been reached, CPP has finished its purpose and degradation may be a prerequisite for cargo release, especially when this is chemically ligated. This is the case for some CPP-drug conjugates, such as CPP-methotrexate or CPP-doxorubicin, that showed less potency compared with the free drug $[51,52]$. However, retention of drug in the conjugate reduced drug efflux and allowed to overcome drug resistance in some tumor cells [51]. Therefore, a proper balance between extracellular protease resistance and intracellular metabolic degradation is a crucial factor to optimize. In this regard, Palm and coworkers [53] have performed a detailed investigation on the extra and intracellular degradation kinetics of two fluorescein labeled CPPs, MAP and penetratin. They found a different pattern of degradation between the extracellular and the intracellular location as well as faster kinetic for the extracellular processing with short half-life values (5-10 $\mathrm{min}$ ). Using specific protease inhibitors, they could identify matrix metalloproteases (MMPs) as major responsible for extracellular peptide degradation. Interestingly, the authors performed a kinetic modeling analysis and conclude that intracellular CPPs may exist in at least two pools, one that is rapidly degraded and another one more stable, either protected by vesicle formation or located in proteolytically low active sites such as the nucleus.

Differences in peptide stability between the extracellular and the intracellular milieu have also been found on pVEC, that was completely degraded extracellularly but remained longer in the intracellular environment either as an intact peptide or as the C-terminal truncated proteolytic limited form [40]. Using a penetratin analog terminally labeled with two different fluorophores, Fischer and colleagues 
dissected the intracellular fate of the studied CPP. Most of peptide degradation was observed within endo-lysosomal compartments with a minor contribution of cytoplasm [54]. Forty percent of peptide remained undegraded, although they could not properly locate it at the subcellular level. Interestingly, this intact peptide could perfectly fit with the stable pool found in the previously mentioned kinetic model [53]. Cellular uptake by endocytic routes could limit CPPs functionality depending on the time they stay in these proteolytically highly active subcellular compartments (late endosome and lysosome). Early and efficient release from the endosome into the cytosol may diminish CPP-cargo degradation and facilitate target accessibility, improving therapeutic functionality. Some cationic CPPs are able to escape from the endosome taking advantage of the anionic lipid-enriched endosome membrane composition and the mild acidic environment $[55,56]$. The possible mechanism of endosomal escape of CPPs has been modeled using a transmembrane $\mathrm{pH}$ gradient [57].

Endosome-lysosome protein degradation was shown early as the major limiting factor for efficient translocation and transactivation activity for Tat protein (the source of the first known CPP). Cellular uptake and functional activity were dramatically increased when incubated with lysosomotrophic reagents such as chloroquine [58]. In the same way, Tat peptide improved its efficiency when an endosomolytic activity was incorporated to its structure $[59,60]$. So, endosomolytic activities were crucial to help providing cytosol accessibility to those CPPs trapped into endosomes. Since endosomal entrapment is a common bottleneck in intracellular delivery of bioactive agents, a number of different strategies have been developed offering a good arsenal of tools to apply to CPPs [61]. Using biologymimicking strategies, CPPs have been modified with fusogenic viral peptides such as hemagglutinin HA2 fusion peptide $[60,62]$ and bacterial toxin translocation domains improving cytoplasm entry $[63,64]$. Acidification sensitive groups were introduced to catch protons and produce osmotic swelling (proton sponge effect) to disrupt the vesicle membrane. They included both, natural biological groups as the amino acid histidine $[59,65]$, with a slightly acidic $\mathrm{pK}_{\mathrm{a}}$, and artificial chemical groups, such as the chloroquine analog trifluoromethylquinoline [66]. Despite these and another $\mathrm{pH}$ triggering mechanisms, other strategies such as the use of multivalent CPPs or the photochemical internalization mediated by photosensitizers are providing promising results [67].

\section{Stabilization strategies}

Peptides are a growing alternative to classical small organic molecules that suffer from a constant attrition limiting the production of new molecular entities. Although they were originally considered poor drug candidates due to their low oral bioavailability and rapid metabolism, pharmaceutical companies have reactivated their interest in these molecules and invested resources to overcome the limitations for peptides to become a real therapeutic option. There are different synthetic strategies to improve 
peptide stability and productivity. Several authors have reviewed this topic for therapeutic peptides, summarizing the main synthetic strategies to improve peptide stability, the most important human proteolytic enzymes involved in peptide degradation and the peptide derivatives marketed or in clinical development $[39,68,69]$. In this review, we focus on the strategies employed to stabilize CPPs, some common to general peptides, but others specifically designed.

In vivo CPP stability depends on factors that influence the proteolytic cleavage. These determinants include sequence, high order structure (conformation), individual chemis tries (unnatural a mino acids, Disomers, chemical bridges, amino acid modifications), routes of entry (presence of different types of proteases and peptidases) as well as the type of cargo and the interaction of CPP with this cargo and other structures (plasma protein, natural or artificial carriers). In an attempt to simplify the features leading to peptide degradation and to explain the rational for the organization's scheme, one can imagine a peptide in a dynamic equilibrium between folded (at least some kind of secondary structure) and unfolded state (Figure 1). Proteolytic enzymes will get easy access to the unfolded molecule, recognize certain amino acid side chains or functional groups and guide to the peptide bond that is the real substrate for the hydrolytic reaction. Any circumstance disturbing this process will reduce or even block the enzymatic activity, preserving peptide integrity and stability. Hence, strategies shifting the equilibrium to the folded state (conformation stabilization), altering the side-chain recognition (amino acid substitution, side-chain modification, stereochemical conversion), modifying the backbone (alternative isosteres and spacers) or simply shielding the peptide to impede the access for the proteolytic enzyme will result in improved stability, consequently increasing the options for successful therapeutic applications. Examples for the application of these methodologies will be described below. In many cases, several strategies were applied simultaneously to maximize the pursued goal. 


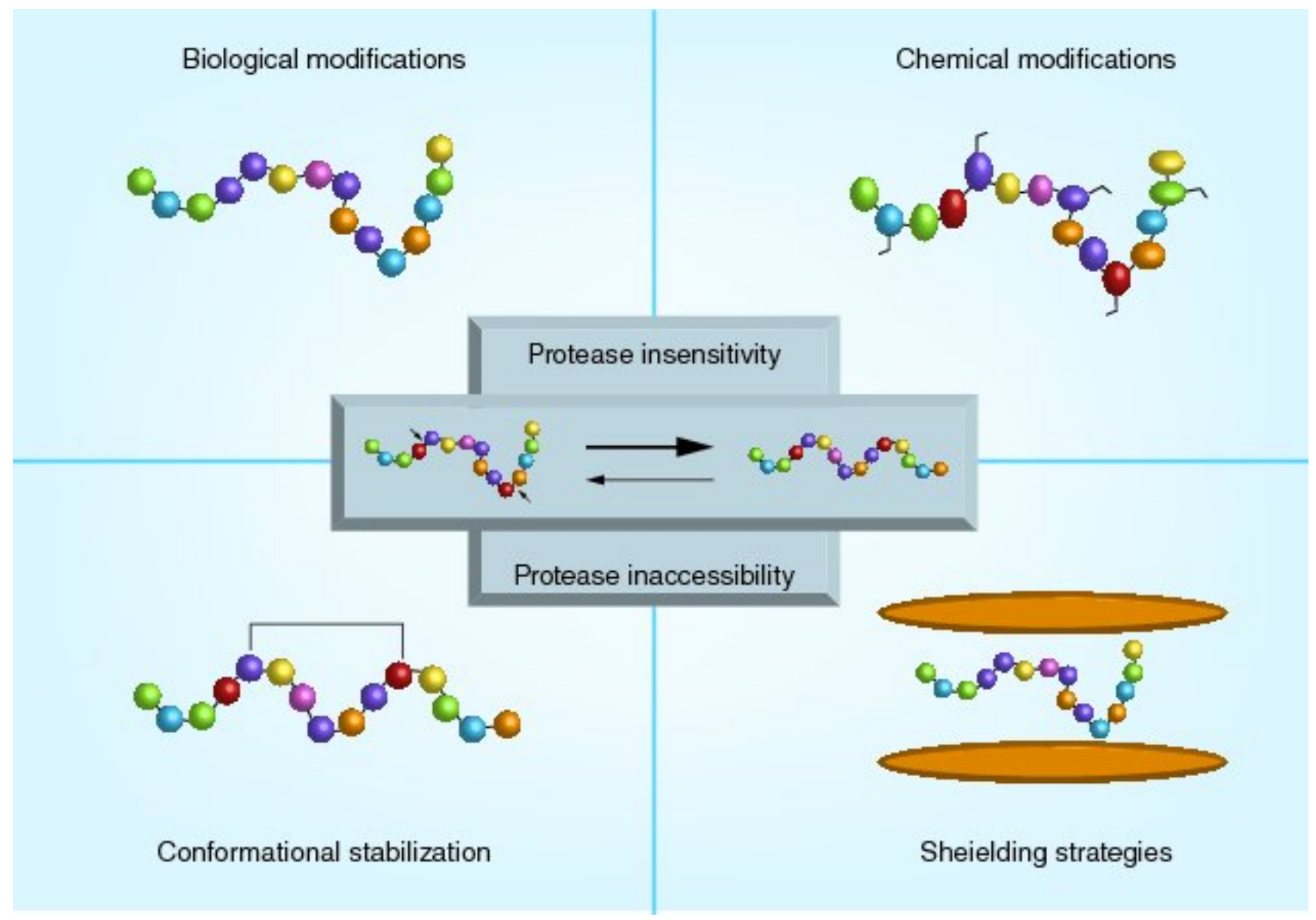

Figure 1. Cell-penetrating peptide stabilization strategies.

Peptide stability depends on the equilibrium between unfolded (left) and folded (right) state. The unfolded state facilitates the access of proteases to the specific cleavage sites (arrows). Two major strategies will preserve peptide integrity: modify the molecule to become unrecognizable to the hydrolytic enzyme or prevent the access of the protease to the substrate (the cleavable bond). The first includes biological (amino acid subs titution) and chemical modifications (stereochemical modification, non-natural amino acids, peptide bond surrogates), while the second refers to conformational stabilization (backbone cyclization, stapled peptides, disulfide formation, polymerization, tertiary structure formation) and shielding strategies (self-assembling, polymer conjugation, controlled shielding).

Biological modifications: sequence optimization by a mino acid subs titution

All peptide sequences are heterogeneous regarding protease sensitivity. Depending on the presence and location of specific amino acids, and the final three-dimensional structure (folding), there are specific points particularly sensitive to enzymatic hydrolysis. Identification of these protease-scissile sites is the primary goal to optimize the sequence for protease resistance. A conservative strategy comprises replacing the sensitive amino acid by an alternative natural residue that provides protection against degradation while keeping the peptide functionality. This sequence optimization can be performed either by random substitution or rational design. The rational strategy has been successfully applied to enhance stability of short antimicrobial peptides [70], a group of membrane penetrating peptides with close similarities to amphipathic CPPs [71,72]. Extracellular proteases in the GI tract 
reduce the efficiency of cecropin A-melittin, a chimeric cell penetrating antimicrobial peptide. Proteolytic stability and antimicrobial potency were improved by substitution of four sensitive residues by tryptophans [73]. In order to localize these critical positions, an in silico tool has been developed to predict peptide stability (measured as half-life) in simulated intestine-like environment [74]. It allows the identification of labile residues and the design of minimum mutations to optimize peptide half-life.

One example of improving peptide stability after detection and modification of the most labile positions of the sequence is $\mathrm{hCT}(9-32)$, a CPP derived from the human peptide hormone calcitonin [75]. A degradation study identified Tyr12 and Phe16 as critical positions for metabolic stability. Replacement of those residues by protease insensitive analogous (D-Phe or N-methyl-Phe) improved up to fourfold the peptide serum half-life [76]. Even the internalization efficiency slightly increased, showing the close correlation between both properties (in the simplest case, prolonging the residence time at cell proximity will improve the chance to bind and penetrate the cell membrane). However, these replacements employed non-natural amino acids. Substitution for regular amino acids has been applied to optimize the stability of DPT-sh1, a natural CPP derived from casein kinase 2a [48]. After identification of an arginine at position 8 as the primary cleavage site, the amino acid was rationally exchanged for a different amino acid (Lys, Asn and Ala), trying to maintain the functional properties. All three mutants improved peptide stability while preserving the penetration capability [50]. Interestingly, a pharmacokinetic (PK) analysis of the mutants showed an improvement of the PK profile and biodistribution compared with the parental peptide, with different PK behavior among the mutants that allowed the selection of the best candidate to perform preclinical studies.

Generation of peptide analogs derived from well-known CPPs has been extensively used but with different purposes: to optimize functionality, to measure as membrane binding potential and penetration, and to minimize cytotoxicity $[77,78]$. The best example is penetratin, that has been modified to enhance nasal absorption of therapeutic peptides, obtaining the best result with a shuffle amino acid substitution [79]. A penetratin derivative designed to improve the efficiency of the exon skipping activity of the oligonucleotide cargo in a Duchenne muscular dystrophy model enhanced it serum stability by replacing the detected protease cleavage sites by protease-resistant residues (substituting L-Arg by D-Arg and L-Lys by L-His at the two major cleavage sites) [80]. Tat peptide has also been modified to improve its membrane penetration efficiency. Modeling Tat structure to obtain a strong $\alpha$-helical amphipathic helix led to the discovery of PTD4, where replacing particular Arg by ahelical promoting residues (Ala) resulted in a Tat analog with a 33-fold in vitro and fivefold in vivo enhancement of transduction potential [81]. Even the simple reverse version of Tat improved the peptide functionality and increased transdermal delivery of cargo proteins [82]. Unfortunately, little attention was paid to the effect on peptide stability, although functional efficiency and metabolic integrity 
are closely related. For instance, optimization of the helical structure improves the cell membrane permeability together with peptide stability. In this sense, a biphenyl cross-linked Noxa-derived peptide designed to improve cellular uptake was rationally modified using information from the crystal structure of the peptide with its target $\mathrm{Mcl}-1$, a member of $\mathrm{Bcl}-2$ family of apoptosis regulator proteins [83]. Replacement of individual exposed residues allowed obtaining analogs that improved simultaneously cell permeability, proteolytic stability and target-specific cell-killing activity.

Peptides made of natural amino acids are cost-effective and are biodegradable, since amino acid as final products can be further metabolized or physiologically recycled into new protein synthesis. As an alternative, the use of chemical modification strategies to improve peptide stability significantly increases the manufacturing cost of peptide, which may limit the clinical application. Naturally modified peptides can be easily obtained by DNA-recombinant technologies, thereby decreasing the production cost for medical applications. In fact, the recombinant production of CPPs is gaining growing attention $[84,85]$. Additionally, fully natural peptides, even with extended protease resistance, will eventually be either metabolized or eliminated by renal clearance, diminishing the risk of systemic toxicity and secondary effects. Therefore, a certain level of metabolic degradation is beneficial to avoid acute and chronic toxicity and, in some circumstances, it might be a prerequisite to release the cargo to allow the maximal efficiency of the payload.

\section{Chemical modifications}

CPPs can be protected from degradation by chemical modification of the original structure. As a general feature, protection can be achieved by any means that make the molecule unrecognizable by proteases. Chemical strategies include incorporation of amino acid stereochemical isomers, non-natural amino acids, blocking the terminal ends (capping), side chain modifications and the use of nonpeptide backbones (Figure 2). The resulting modified peptide should preserve the functional activity and escape from the metabolic control. However, it is not a natural peptide anymore. As a matter of fact, the more distant from a natural peptide the more resistant a CPP will become to enzymatic cleavage [86]. 


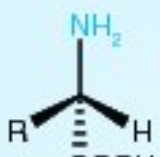

$\overline{\mathrm{COOH}}$

L- $\alpha$-amino

acid

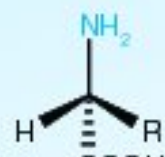

D- $\alpha$-amino acid

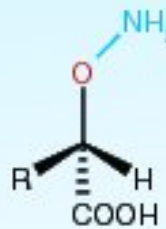

$\alpha$-aminoxi acid $\alpha$-amino acid

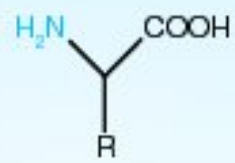<smiles>[R]C(N)C([R2])C([R])C(=O)O</smiles>

$\gamma$-amino acid<smiles>[R]C(NC(=O)C([R])NC)C(C)=O</smiles>

Natural peptide<smiles>[R7]N(C)CC(=O)N([R7])CC(C)=O</smiles>

Peptoide $\beta$-amino acid<smiles>[R]C(N)C([R])C(=O)O</smiles>

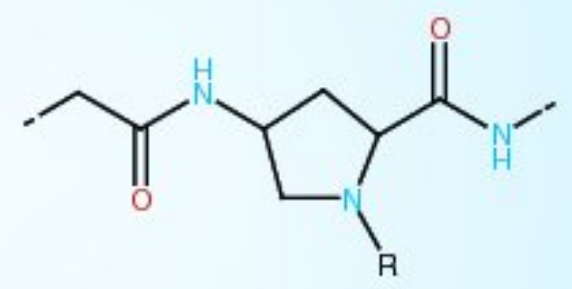

$\gamma$-amino proline derived peptide<smiles>CNC(=O)C1CCCN1CCCNC(C)=O</smiles>

Aminopropyl prolyl peptide spacer<smiles>CCOC(=O)NC</smiles>

Carbamate-based peptide spacer

Figure 2. Representative structures used to preserve peptide stability.

Some amino acid analogs and peptide bond surrogates are shown together with the reference natural structures (L- $\alpha$-amino acid and regular peptide).

\section{Stereochemical modification}

Stereochemical orientation is a priority for substrate recognition and enzyme binding. Peptides in nature are mostly built with L-amino acid and most proteases only recognize substrates with this configuration. Substitution of L-amino acids with D-isomers changes peptide conformation (Figure 2) and makes the molecule invisible to proteases increasing its half-life in physiological environments. For this reason, synthesis of partial or complete D-isomers of CPPs has become a frequent strategy to overcome protease sensitivity. We have already mentioned the in vitro stability improvement in hCT(9-32) obtained by replacing the protease sensitive residues at position L-Tyr12 and L-Phe16 by D-Phe [76]. The same group further demonstrated that the acquired protease resistance translated into prolonged in vivo half-life compared with the parental unmodified peptide, although both peptides were metabolized to some extent by the hepatobiliary tract [87]. A more detailed analysis allowed the identification of a major cleavage site at position 17 of the chemically modified peptide that showed either a different pattern of degradation between in vitro and in vivo studies, the appearance of new cleavage sites when the primary sites are protected, as observed with penetratin [45], or both 
simultaneously.

Tat peptide, the first discovered CPP, has been synthesized as an all-D enantiomer obtaining a significant resistance to proteases that resulted in a higher functional efficiency [87]. Penetratin was also synthesized as an enzymatic resistant D-form and orally co-administered with insulin in mice enhancing its absorption. Both isomeric forms, $L$ and $D$, worked as oral absorption enhancers, but while natural L-penetratin doubled insulin half-life in intestinal fluid, D-penetratin enhanced fourfolds the basal value [31]. The same group further analyzed the safety profile of this D-substituted CPP as oral absorption enhancer in mice by oral administration during seven consecutive days [88]. They did not find hepatic damage, demonstrating the feasibility of the repeated use of a D-CPP as a safe strategy to enhance oral absorption of co-administered therapeutic peptide. Similarly, the all-D enantiomeric version of the proline-rich CPP SAP was compared with the original L-peptide [89]. D-SAP was dramatically more stable in human serum and maintained similar internalization properties, including nondetectable toxicity in preliminary in vivo studies [90]. On the other hand, the protease resistance provided with the chiral modification of the arginine-rich CPP R9 (D-R9) translated into a much faster transduction than parental L-R9 in all tested cell-types [91]. This potent stabilization was exploited for D-R7 to support the aggressive metabolic environment of the skin and facilitate topical delivery of cyclosporin A, which has poor skin penetration [92]. Metabolic stability may differ drastically between the natural L-peptide and the D-enantiomer. In an extensive stability study performed with octaarginine and several derivatives, Purkayastha and coworkers observed that neither the original L-R8, with a halflife less than $0.5 \mathrm{~min}$, nor the all-D-R8, with a half-life greater than 7 days, were acceptable for clinical applications [93]. A very short half-life is not sufficient to ensure proper bioavilability and complete protease protection, leading to body accumulation, which is not medically desirable. The authors proposed an intermediate strategy by combining both enantiomers in mixed diastereoisomeric L/D-R8 derivatives and found several molecules with half-life ranging between 8 min and $5.5 \mathrm{~h}$ as suitable candidates for medicinal applications.

$L$ to $D$ conversion may have an impact in peptide activity, depending on the relevance of the stereochemical recognition in peptide functionality. In order to compensate for these structural changes, the retroinversion $(\mathrm{RI})$ concept can be applied. It comprises reversing the normal sequence from $\mathrm{N}$ - to C-terminus, once the natural L-amino acids have been replaced by the D-isomers. So, side chain topologies of the natural peptide are guaranteed. Although this retroinversion concept has been previously used with CPPs [94], a careful comparative analysis of representative CPPs in both chiral versions showed surprising results. Despite the gain in stability, certain RI-CPPs, in contrast to the parental L-CPPs, induced a severe cellular toxicity characterized by loss of mitochondrial transmembrane potential, decreased metabolic activity, different morphological changes and induction 
of apoptosis [95]. Contrary to the general assumption, studies with mastoparan and mitoparan have shown that while inverso transformation (D-isomer) retained the biological activity, the retro-inverso version failed to preserve the cell membrane translocation efficiency [96]. Similarly, M918, a CPP derived from the tumor suppressor protein p14ARF, decreased the cellular internalization potential when transformed into a retroinverted version [95]. L to D conversion may cause the loss of peptide cell permeability. That was the case of MAARL peptide that was unable to penetrate cells in its $D$-isomeric form, suggesting the requirement of a stereoselective interaction with a chiral receptor to trigger cell entry [97]. In a recent study with a transferrin receptor specific CPP that crosses the BBB, modifications of the natural peptide, by either $\mathrm{N}$-methylation of protease-sensitive positions, D-enantiomer or retroinversion, improved peptide half-life from 30 min to $12 \mathrm{~h}$ (N-methylation) or more than $24 \mathrm{~h}(\mathrm{D}$ and RI). However, only the RI version was able to duplicate the permeability in a BBB model, showing that RI peptide reached an optimal balance between stability and potency, which is mediated by the right topological recognition by the transferrin receptor [98].

Chirality switching by L- to D-amino acid exchange has to be evaluated in every individual situation to avoid undesired effects. A careful analysis of multiple chiral substitutions of amino acids has been recently performed on $\mathrm{p} 28$. This 28 amino acid long CPP is a fragment of azurin that binds and protects p53 from proteosomal degradation and is currently under clinical evaluation [99]. The authors observed a decline in intracellular uptake, even with a single D-amino acid substitution, that was cell line dependent [100]. The effect changed with the amino acid position and its impact on the overall peptide chirality, stressing the importance of these features for the design of D-substituted analogs of CPPs. This preferential cellular uptake of all-L- versus all-D-CPPs was previously observed for cationic CPPs, without showing differences in binding affinities to plasma membrane heparan sulfate [101]. Since binding was equivalent for both isomers, the authors proposed a two-step internalization model with an initial binding to heparan sulfates on the plasma membrane followed by a chirality dependent endocytic internalization.

\section{Non-natural amino acids}

The use of amino acids that are not incorporated by the physiological protein synthesis machinery implies that will not be recognized by regular protease degradation systems. These non-natural amino acids include alternative a-amino acids, with unnatural side chains, and those with the amino group attached to a carbon different to the one in alpha position (Figure 2). The former comprised a side chain substitution at the a-carbon maintain the backbone topology, while it is modified in the latter, providing a second level of protease protection. $\alpha$-Substitution allows the replacement of natural side chains of $\alpha-$ amino acids by different groups, usually alkyl groups. The most representative example is the $\alpha$-amino isobutyric acid (Aib). Aib is a known helix promoter and the induced conformational constraint may 
additionally contribute to peptide stabilization [102]. This strategy was applied to mastoparan, whose activity strongly depends on the formation of an amphipathic helix. Substitution of alanine by Aib at position 10 and increasing the net positive charge by introducing two Lys residues at positions 5 and 8 generated the mitochondriotrophic CPP mitoparan, a mastoparan analog with a more stable helical structure and enhanced amphiphilicity that translated into improving functionality [103]. Another example of non-natural $\alpha$-amino acid is 1-aminocyclopentane-1-carboxylic acid $\left(\mathrm{Ac}_{5} \mathrm{c}\right)$. Incorporation of this cyclic analog into a CPP comprising a triple repeat of L-Arg-L-Leu-Ac ${ }_{5} C$ generated an efficient cell delivery agent with improved serum stability [104]. As an alternative to $\alpha$-amino acids, $\alpha$-aminoxy acids represent an excellent structural scaffold to build metabolically stable peptides [105]. They have been used to construct guanidinium-rich CPPs trying to improve stability compared with the analogous oligoarginines. Introduction of these groups alternated with natural a-amino acids resulted in hybrid peptides that display good protease resistance, low cytotoxicity and an efficient cytosolic distribution, probably due to a direct membrane translocation mechanism [106].

The second strategy employed $\beta$ - and $Y$-amino acids. They can acquire different topologies depending where they have attached the side chain ( $\alpha, \beta$ or $y$-carbon). $\beta$-Amino acids were originally used to explore the effects of conformational stability and geometry of the guanidinium groups displayed on oligoarginine CPPs [107]. Incorporation of $\beta$-alanines into R8 increased the metabolic stability of CPP-morpholino oligomer conjugates [108]. In the search for enzymatically stable CPPs, $\beta$ amino acids ( $\mathrm{N}$-alkylated $\beta$-alanine) were introduced between $\beta$-amino acids to obtain peptide chimeras as proteolytically stable alternatives to Tat peptide. In addition to the stabilization improvement, the chimeras penetrated cells more efficiently than Tat, showing different membrane permeabilization properties [109]. Y-Amino acids have also been considered for the design of metabolically stable CPPs. Based on cis-y-amino-I-proline, functionalized at the pyrroline amine to mimic the side chains of natural amino acids, these $\mathrm{Y}$-peptides entered cell by different mechanisms and showed higher protease resistance and lower toxicity than the reference Tat peptide [110].

\section{Modified peptide backbones (pseudopeptides)}

Despite lateral groups of the amino acids confer specificity for protease degradation, is the peptide backbone (peptide bond) the real substrate for the hydrolytic reaction. Then, any modification of this structure (isosteric surrogate, linker substitute.) will protect the peptide for the proteolytic degradation. Alkylation at the nitrogen atom of the peptide bond is a simple modification with a low impact in the overall structure, but sufficient to safeguard against proteolytic processing, with minor effect on sidechain spatial orientation and biological activity. There are several examples of therapeutic peptides that become resistant to enzymatic degradation after $\mathrm{N}$-methylation of proteolytic sensitive residues [86]. 
The most frequent application of $\mathrm{N}$-methylation is the modification of cyclic peptides, trying to resemble the structure of cyclosporin. The combination of macrocyclization and multiple $\mathrm{N}$-methylation provides a double effect, membrane permeability and resistance to enzymatic degradation, a strategy employed to design orally available peptide-based medicines with optimal intestinal absorption [111]. N-alkylation has been mainly applied to CPPs in the context of peptoids, pseudopeptides that contain $\mathrm{N}$-alkylated glycines linked by peptide bones. Thus, the side chains are moved from the natural $\alpha$-carbon position to the nitrogen atom of the peptide backbone. Since the chirality of the a-carbon is lost, peptoids are not always perfect mimics of the natural peptides. The first cell penetrating peptoids (CPPos) were discovered by screening a combinatorial library of cationic peptoids for new reagents to deliver genes into cells [112]. Since then, several groups have reported the use of different type of CPPos due to the easy synthesis and the diversity of available side chains [112-116]. They tried to resemble natural CPPs by displaying lysine- or arginine-like side chains. Interestingly, side chains longer than the Arg analog gave better efficiency in cell penetration, even higher than the D-arginine oligomer R9 [113].

Peptide bond reduction is another simple way to generate a surrogate peptide backbone. It has been used to obtain linear pseudo-oligolysines as gene delivery vectors [117]. However, within cationic amino acids, arginines are superior to lysines for cell binding and uptake, making guanidinium groups the preferential choice for efficient cationic CPPs [118,119]. Accordingly, a number of different types of guanidinium-rich transporters have been developed and demonstrated good efficiency in transporting payloads across cell membranes [120]. Among them, there are some that deserve special attention. In an attempt to evaluate the role of backbone spacing in cellular uptake of arginine oligomers, Rothbard and coworkers introduced non- $\alpha$-amino acids between arginine residues as molecular spacers, resulting in improved cell penetration [121]. This modification incorporated conformational freedom to the backbone facilitating guanidinium headgroups orientation toward the negative charges of membrane surface, allowing different conformations required for efficient translocation. The main risk of enhancing conformational flexibility is the increased sensibility to protease degradation, but this feature was avoided by the use of these non-natural amino acids. A new concept of Arg-rich molecular transporters arose with a general scheme $[R-X-R]_{n}$, where $X$ was the unnatural amino acid acting as spacer, being $\omega$-aminohexanoic acid (Ahx) the more successful candidate in the first set of analyzed groups, further overcome by chiral N-aminoalkyl proline derived spacers [122]. Using the same [R-X$\mathrm{R}]_{\mathrm{n}}$ scheme, amide linkages were replaced by carbamate, as peptide bond surrogate, with additional improvement in stability and cell permeability [123].

\section{Conformational stabilization}

Every polypeptide chain adopts a specific conformation (native conformation) depending on its 
sequence, conferring unique stability properties. The primary determinant for peptide biological activity and bioavailability is this native conformation. Small peptides can hardly adopt a stable conformation in solution and tend to maintain an unfolded state. Conformational flexibility of peptides makes them metabolically unstable and restricts their use as therapeutic agents for clinical applications. Therefore, any interactions (intra- or intermolecular, with itself or with other external components) that help adopt a stable folded conformation will positively contribute to peptide global stabilization and diminish the risk of peptide degradation and metabolization. Based on conformational constraints, several strategies have been applied $[124,125]$. In this context, intramolecular bonds are an effective tool to reduce conformational flexibility. This can be used to generate cyclic molecules (cyclization) or to stabilize established secondary structures (disulfide formation, stapled peptides). Intermolecular interactions may also contribute to stabilize the folded conformation. Among these interactions, we could highlight those established with the payload and the self-interactions contributing to high order structures. CPP_ cargo interactions are payload-dependent and are not considered in this review, but their putative positive effect is important to keep in mind. Even the extension of a linear peptide with additional natural L-amino acids may contribute to establish a more stable folded structure and have a protective effect. On the other hand, strategies to generate higher order structures (self-assembling CPPs, nanoparticles) will be considered from the shielding point of view and included in the corresponding section. It should be noted that, in addition to molecule stabilization improvement, conformation plays a crucial role in peptide permeability providing an extra benefit to the overall functional success of the therapeutic shuttle.

\section{Backbone cyclization}

End-to-end cyclization has been employed by nature to confer superior stability and cell permeability to active peptides with different functionalities. Cyclosporin, a natural poly-N-methylated cyclic peptide, is a perfect paradigm of stable peptide. Found as a natural product obtained from a fungus, it has three important characteristics that preserve metabolic stability: cyclization, use of D-amino acids and multiple $\mathrm{N}$-methylation. All three modifications have been applied to confer stability to CPPs, either independently or simultaneously. Mimicking cyclosporin, several poly-N-methylated cyclic peptides have been developed with outstanding metabolic stability and remarkable intestinal permeability resulting in potent orally bioavailable peptide-based therapeutics [111]. End-to-end cyclization was applied to classical Arg-rich CPPs (Tat, R10) inducing a covalent linkage between an extra lysine and glutamic acids incorporated in the edges [126]. The new cyclic CPPs showed higher transduction efficiency compared with linear counterparts. Conformational restriction, despite conferring enhanced protease resistance, provide a maximal separation of guanidinium groups that facilitate cell entrance by nonendocytic routes, allowing rapid bioavailability of the cargo in cytosol and nucleus [127]. Newly 
designed macrocyclic CPPs led to the discovery of efficient protease-resistant cell transporters such as $\mathrm{cF} \mathrm{R}_{4}$, a short peptide comprising a Phe, a l-2-naphthyl-Ala $(\Phi)$ and 4 Arg, with higher cell penetrability than linear oligoarginine R9 and superior stability [128]. This peptide motif can be used to deliver cargoes introduced endocyclically (inserted within the ring), exocyclically (attached to a side chain of the cyclic CPP) or as a bicyclic design, providing an excellent cell penetration efficiency, mediated by early endosome escape, associated to a strong protease resistance with minimal toxicity [129]. The bicycle design further contributes to increase conformational rigidity and divide the molecule in two different moieties with separated functionalities, one responsible for cell recognition and penetration (CPP moiety) and the effector moiety that can recognize specific intracellular targets. Bicyclic peptides have been applied to target intracellular proteins such as Pin1 isomerase and protein tyrosine phosphatase 1B [130].

An interesting group of cyclic CPPs derive from cyclotides, a family of naturally stable disulfide-rich cyclic peptides. Cyclotides are small (less than 40 residues) plant produced miniproteins that combine two structural features leading to a remarkable physical, chemical and enzymatic stability: head-to-tail cyclization and three disulfide bridges arranged in a knot. Together, it defines a conserved motif called cyclic cystine knot (CCK). Due to the plasticity of this structural motif and the good tolerance for amino acid substitution, CCK can be used as a scaffold to stabilize exogenous bioactive peptides for pharmaceutical applications [131]. Some cyclotides have been reported to cross cell membranes and constitute a new family of CPPs [132]. The representative member MCoTI-II has been characterized and re-engineered to graft into the loop 6 a p53-derived helical peptide able to disrupt the interaction between $\mathrm{p} 53$ and its negative regulator $\mathrm{Hdm} 2 / \mathrm{HdmX}$. The engineered cyclotide was able to activate p53 in vivo by binding to $\mathrm{Hdm} 2 / \mathrm{HdmX}$ with low nanomolar affinities and suppress tumor growth in a murine xenograft model [133]. The scaffold has been additionally modified introducing extra positive charges $(R)$ in different loops (mainly loops 1 and 2 ) to improve the cell penetration activity $[134,135]$.

\section{Stapled peptides}

Another way to preserve peptide stability by conformational restriction comprised immobilizing specific functional secondary structures, such as a-helix, shifting the folding equilibrium to the proteaseprotected form (Figure 1). There is a diversity of chemical strategies used to stabilize $\alpha$-helices: covalent cross-linking between side-chains of residues located at the same face of the helix, including disulfide bridges, lactam tethers, biphenyl linkers and all-hydrocarbon stapling [125]. The latter uses $\mathrm{N}$ methylated amino acids to build a rigid 'staple' through a ring-closing olefin metathesis of either 8 or 11 carbons, clicking residues with one or two helix-turn distance. All-hydrocarbon stapled peptides were originally designed to enhance helicity and improved target affinity and metabolic stability [136]. In 
addition, stapling confers cell penetration functionality by rigidifying the peptide structure in a way similar to the backbone cyclization. Therefore, stapled peptides could be considered as noncanonical CPPs since they are not designed as shuttle to transport different kind of cargoes inside cells, rather bioactive CPPs with dual functionalities within the same sequence: cell penetration and target inhibition. However, since this technology is not applied to regular CPPs to improve metabolic stability, we are not going to expand this topic and we recommend some of the excellent reviews for further reading $[137,138]$. It should be mentioned that not all stapled peptides are endowed with cell permeability capacity [139]. Some groups are making efforts to understand the mechanisms of cellular uptake triggered by peptide stapling [140]. Moreover, cellular uptake of staple peptides can be further enhanced by conjugation with polyamines preserving biological activity without apparent toxicity [141].

\section{Disulfide formation}

Disulfide formation stabilizes peptide structure reducing conformational variability and diminishing the accessibility to proteolytic enzymes. It is a natural mechanism to stabilize conformation in proteins and provides resistance against physical, chemical and enzymatic aggressions. Disulfide bridges can be established intra- and intermolecularly. Engineering an intramolecular disulfide in the therapeutic peptide GLP-1, a cyclic conformation analog (TY70517) was generated enhancing in vivo half-life from $2 \mathrm{~min}$ to $52 \mathrm{~h}$ [142]. Disulfide-bound homodimeric Tat analogs have been generated incorporating an extracysteine residue to Tat peptide, either at $\mathrm{N}$ - or C-terminal edges (Tat-NTHD and Tat-CTHD, respectively), [143]. Both modified peptides were superior as gene delivery systems than parental Tat or a cyclic Tat obtained by intramolecular disulfide formation between two Cys residues introduced in each terminal position. Similarly, a C-terminal cysteine has been incorporated into another classical CPP, penetratin, and the analogs PenArg and EB1. It induced peptide dimerization by disulfide bridge formation generating a 'chelate effect' that increased peptide affinity to nucleic acids and greatly improved transfection efficiency. Disulfide-induced dimerization enhanced thermodynamic stability and even improved endosomal escape, contributing to overall peptide stability and transport efficiency [144]. Cyclic cystine knots are the best application of disulfide formation to enhance peptide stability by conformational constraint generation. As mentioned above, the CCK topology found in cyclotides provides an ultrastable cell penetrating scaffold to introduce bioactive peptides into cells [131-135]. Disulfide formation can be applied to obtain CPP polymers as mentioned in the corresponding section.

In vivo disulfide shuffling (due to re-dox state, the presence of thiol-disulfide isomerases and re-dox buffers such as glutathione or thioredoxin systems) is a potential limitation of the conformational restriction induced by disulfide formation. However, it may also turn into an advantage to facilitate cargo release in the cytosol, where glutathione levels are elevated, either by destabilizing CPP or detaching payloads bound by S-S linkages. 


\section{Branched polymers \& dendrimer formation}

The small size of CPPs and the conformational flexibility negatively influence peptide stability. Thus, increasing overall size and rigidity will contribute to strengthen the molecule. As we mentioned above, simple dimerization improved peptide stability and enhanced cell permeability $[143,144]$. Increasing size and structure complexity by ordered (dendrimer) or unordered branch formation should enhance these characteristics. In addition, concentration of CPP moieties in the same structure would increase avidity through multivalency and should further potentiate membrane binding and cellular uptake. This effect has been observed in CPP-decorated nanoparticles [4,145] as well as in linear scaffolds [146]. Density of CPPs within the polymer directly correlates with protease protection. So, introduction of canonical CPPs (Tat, R8) into a high-density brush polymer rendered peptides resistant to proteolysis without affecting cell penetration capacity [147]. The authors observed that resistance derived from the high packing density of peptides prevented access to the active site of proteases and can be modulated to fine tune the protective effect.

Aside from decorating polymers with CPPs, CPPs themselves can be modified to generate branched structures. Improvement in the membrane translocation efficiency of the human calcitonin-derived CPP $\mathrm{hCT}(9-32)$ by branched modification comprising the addition of an oligocationic side-branch attached to the main peptide chain at the K18 position [148]. Lysines are prone to polymerize both linearly, making peptide bonds with the a-amino group, or branching through the $\epsilon$-amino of the side chain. So, they can build a perfect scaffold for cationic branched polymers with cell penetration properties. Based on lysine double amino groups, peptide dendrimers have been built as multivalent scaffold for short peptide branches resulting in structures with enhanced cellular uptake, lower cytotoxicity and higher stability compared with their linear counterparts [149]. The spherical three-dimensional morphology of dendrimers generated a globular topology that hampered the access of proteases and preserved peptide stability. Dendrimer structures nucleated by lysines have been developed with branched arms having one or more R-Ahx-R motifs. Branched topology together with the use of proteolysis-resistant spacers (Ahx, $\beta$-Ala) resulted in strong stability in serum [150]. Guanidinium groups, the functional moiety of the arginine side chain, are more effective than lysine $\epsilon$-amino group in CPP-mediated membrane translocation [118]. Because of this, guanidines are perfect candidates for cell penetrating structures and dendrimers have been functionalized with them using different types of backbones: polyamides, poly(propyleneimine), polycarbonate or polyamidoamines (PAMAM). The resulting structures showed good efficiencies and a promising future [151].

Incorporation of cysteines and controlling disulfide formation allowed the formation of branched structures. A modified oligoarginine was designed based on a repeating unit composed of a $\mathrm{D}$-isomeric nona-D-arginine flanked by cysteines: Cys-(D-R9)-Cys. The monomer was treated by DMSO-mediated 
oxidative polymerization to obtain a $95 \mathrm{kDa}$ disulfide-branched polymer called reducible poly(oligo-Darginine) (rPOA). The generated branched peptide improved stability and in vivo gene delivery efficiency, showing superior gene expression levels than polyethylenimine (PEI), a reference standard for gene transfection [152]. Pro-rich peptides, a family of efficient CPPs [153], have also been modified to generate dendrimer structures, using cis-4-amino-L-proline as branching units, decorating the surface with Arg-rich sequences [154]. The peptide-based biodendrimer was stable and efficient in cellular uptake, but presented a certain level of toxicity at high concentration that could be modulated by regulating the density of guanidinium groups at the surface.

\section{Tertiary structure formation: miniprotein design}

When the cargo is a peptide and is included in the same linear sequence of the CPP, the final size of the molecule may allow the formation of a tertiary structure that helps stabilize the complete molecule and protect it from protease degradation. This is particularly interesting for engineering miniproteins, a field that is showing promise as emerging tools for therapeutic applications [155]. Miniproteins were originally designed for target receptors and used as scaffolds to present ligands in a stabilized and bioactive form, but lacking efficient cellular uptake. Incorporation of a CPP into the miniprotein sequence can provide a double benefit: the miniprotein scaffold may stabilize the CPP sequence while the last ensures cell penetration of the therapeutic domain for intracellular targeting. This concept has been demonstrated with a miniprotein derived from avian pancreatic polypeptide (aPP), a 36-residues thermostable miniature protein composed of an N-terminal type II polyproline helical structure (PPII helix) and a C-terminal a-helix. Rational incorporation of cationic residues (arginines) either into the PPII helix or the aPP a-helix rendered the structure extraordinarily cell permeable while preserving conformational stability [156,157]. A second example, mentioned above, are the cell-permeable cyclotides based on MCoTI-II which have been modified to improve cellular uptake by rational substitution of arginine residues into permissive loops [134,135]. Cystine knots have a good tolerance for amino acid substitution and this high plasticity allows further engineering by scaffold swapping to improve pharmacokinetics properties such as higher target affinity, enhanced stability or modulated renal clearance [158].

\section{Shielding strategies}

A last type of modification to protect CPPs from protease attack comprises restricting the access of the enzyme by physical shielding. It can be obtained through three distinct general strategies: formation of ordered aggregated structures induced by self-assembling of monomeric CPPs, conjugation with protective polymers, and incorporation in suprastructures where CPPs are hidden and further released at the target place by specific triggering factors. 


\section{Self-assembling CPPs}

Disordered aggregation is the main reason of physical instability and causes loss of biological activity. However, the formation of an ordered controlled aggregation state may have the opposite effect and acts as an efficient mechanism of peptide stabilization, making folded conformation steady and protecting monomeric sequences from proteolytic degradation. Controlled aggregation may be achieved by self-assembling elements, either attached to the CPP or incorporated within its sequence. Additionally, noncovalent self-interaction generates multivalent CPPs, as happens with branched CPPs and dendrimers, which contributes to facilitate cell entrance and endosome escape [67]. CPPs can be conjugated to self-assembling elements that organize in ordered supramolecular structures or, together with other complementary elements, be incorporated into more complex nanocarriers. The most frequent strategy to induce self-assembling was the conjugation with a lipophilic domain at a CPP terminal edge. Examples can be found in most canonical CPPs. Stearyl-TP10 and stearyl-R9 formed stable nanoparticles with plasmids for efficient gene transfer [159]. Myristoylated Transportan leaded to stable encapsulation of siRNAs and efficient targeted delivery of cargo to brain cells, bypassing the BBB [160]. Conjugation of oligoarginines with fatty acid chains through a $\beta$-Ala residue at the $N$-terminal edge, enhanced their metabolic stability and cell penetration efficiency [161]. These lipo-oligoarginine peptides were further optimized by introducing different combination of D-Arg residues in the peptide backbone [162]. Coupling of a four octanoic acid (C8) tail at the N-terminal lysine (using both $\alpha$ and $\epsilon$ amines) of Tat induced the formation of well-defined nanofibers able to encapsulate small hydrophobic drugs, such as paclitaxel, and to efficiently transport it into cells [163]. Fusion of Tat coil with a selfassembling stiff poly-proline rod generated nanocapsules that worked as efficient carriers for entrapped hydrophilic molecules [164]. Similarly, T $\beta P$, a chimeric peptide composed of a CPP (Tat), a flexible linker (GSGG) and an amphipathic $\beta$-sheet self-assembly block ([FKFE] $]_{3}$ ), made nanoribbon structures that function as efficient intracellular carriers for encapsulated hydrophobic molecules [165]. As a last example of these type of strategies, conjugation of small CPPs $\left(R 6,\left[R_{2} G\right]_{2}\right)$ with collagen-like folding domains (multiple [Pro-hydroxyPro-Gly $]_{n}$ repeats) induced the formation of a collagen-like triple helical conformation that protected the peptide from protease degradation and facilitated cellular uptake with lack of toxicity [166].

Small peptides are attractive building blocks to generate well-ordered nanostructures with different supramolecular architectures, including tubes, fibers, tapes, spheres (vesicles, micelles) or sheets [167]. Some CPPs, especially those with a high amphiphilic character, have a tendency to aggregate, depending on the solvent, the concentration and the interaction with other structures (cargoes, membranes). The aggregation state will condition its stability and membrane penetration properties, although in most cases this has not been deeply characterized [168]. This was not the case for D-SAP, 
a protease-resistant amphipathic Pro-rich CPP, which adopted a typical polyproline II secondary structure and formed fibrils of 16-20 nm width with variable length [89]. In certain circumstances, the formation of supramolecular structures is induced by the noncovalent interaction between a cationic CPP and an anionic cargo. This feature has been particularly exploited with nucleic acids, as plasmids and siRNAs. Helical amphiphatic CPPs such as RAWA [169], C6M1 [170] or CADY [171] have demonstrated their cell delivery efficiency after forming stable supramolecular complexes with anionic cargoes. The self-assembly of CADY molecules around siRNA has been studied in more detail and found a 'raspberry'-like nanoparticle architecture around $150 \mathrm{~nm}$ diameter, composed of smaller spherical elements of 20-25 $\mathrm{nm}$ [172].

\section{Polymer conjugation}

Surface modification by polymer conjugation is a classical strategy to sterically shield peptides and proteins from proteolytic enzymes. It improves the pharmacokinetic profile by increasing the overall molecular mass, extending circulating half-life and bioavailability, and delaying elimination by renal clearance. Polyethylene glycol (PEG) is the most frequently used polymer employed to this end. Conjugation of Tat peptide with PEG and phosphatidyl ethanolamine (TATp-PEG $1000-P E)$ stabilized the peptide increasing half-life by threefold compared with the unconjugated peptide. A further protection was observed (100-fold increase in half-life) when the conjugated peptide was additionally shielded by incorporation into mixed micelles with $\mathrm{PEG}_{5000} \mathrm{PE}$. Therefore, the CPP appeared highly protected against proteolysis if the PEG block in PEG-PE is longer than the PEG block in the TATp-PEG-PE conjugate [47]. The same team further demonstrated a direct correlation between PEG length used for shielding and proteolytic protection [173]. However, PEGylation has important drawbacks for CPPs and other cell delivery devices: it inhibits cellular uptake and endosome escape [174]. In order to avoid this, delivery systems have evolved to introducing targeting ligands and cleavable PEG bonds to be removed at the target place allowing cell penetration. An example of such a design is the multifunctional pH-sensitive PEGylated liposome modified with a CPP moiety (Tat) and a target-specific moiety (mAb 2C5) for specific delivery of chemotherapeutic drug into cancer cells [175]. This 'smart' concept of nanoparticle design will be developed in more detail below.

\section{Controlled shielding: stimuli-responsive CPP activation}

In order to avoid CPP degradation and unspecific cellular uptake of the valuable therapeutic cargo, different strategies have been developed in which CPPs are temporary protected and inactivated to be later reactivated at the target place by either internal or external signals (Figure 3). Thus, 'smart' nanocarrier systems have been designed that include CPPs and cargoes within particles (liposomes, nanoparticles, dendrimers) engineered in such a way that nonspecific CPPs are sterically shielded by a 
polymer or a targeting antibody. Once the target site has been reached, the protective moiety should be removed by a stimulus-sensitive signal exposing the CPP to the membrane surface and triggering cell entrance. Stimuli can be local (presence of specific matrix metalloproteinases, acidification, hypoxia) or external signals modulated by the therapist (temperature, light, ultrasound, radiofrequencies). Since these strategies were designed to improve targeting as a primary goal and there are some excellent reviews covering this topic [4,6]. Here we will only briefly mention some of the more prominent examples.

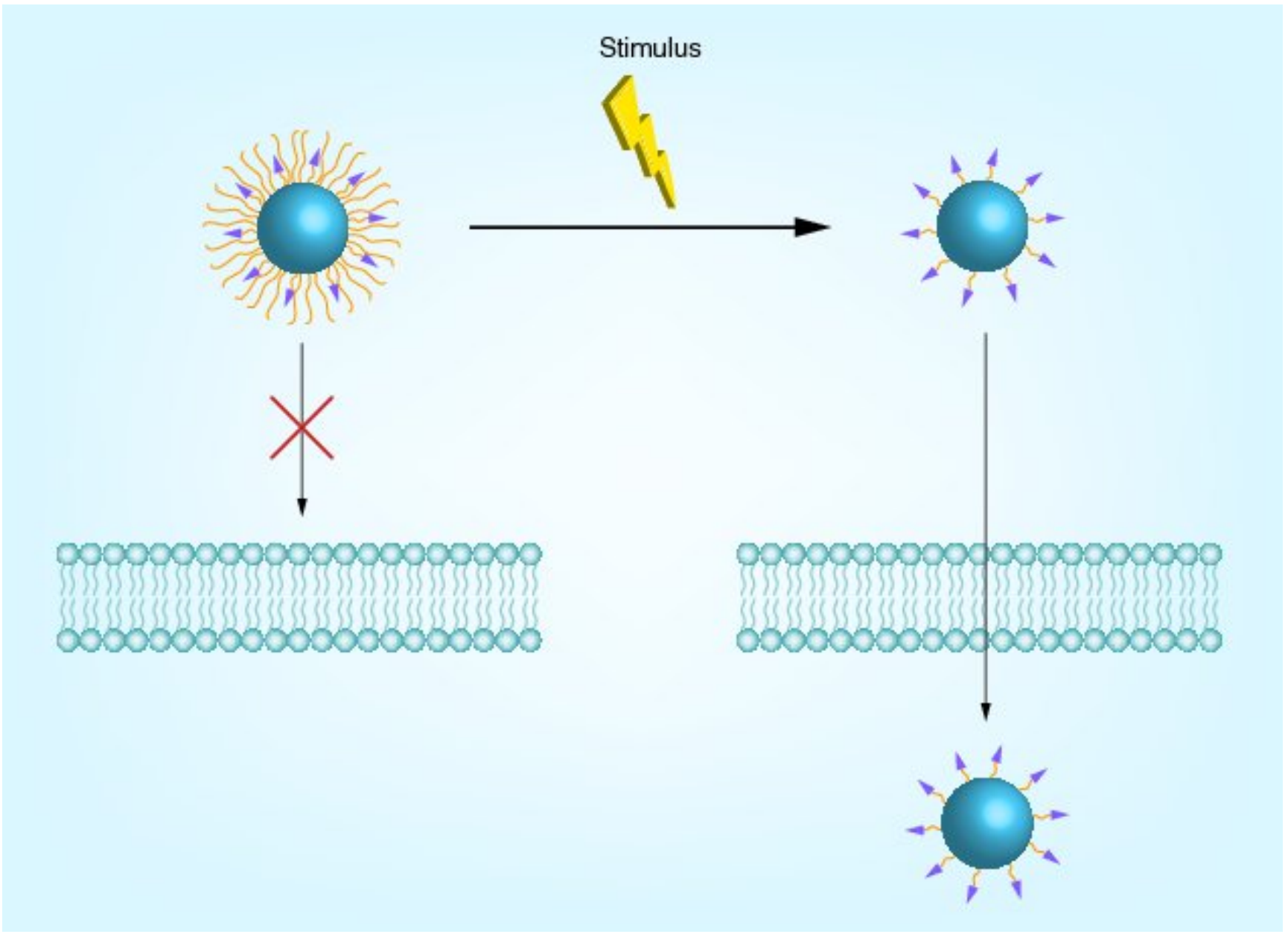

Figure 3. Controlled shielding strategy.

Schematic representation of the general strategy associated with the stimuli-responsive CPP activation. The nanocarrier is formed by a core (blue sphere) where cargo is transported and decorated with a CPP (purple arrow) and protective groups (orange lines), making a shielding corona that preserves CPP stability and avoids binding to cell during circulation. Once the target site has been reached, a specific stimulus (local or external) triggers the exposure of CPPs (unshielding) facilitating cellular uptake.

Activatable CPPs is a concept originally developed to provide tumor selectivity. It is based on the generation of a linear peptide comprising a polycationic CPP and a polyanionic sequence separated by a protease-sensitive linker that is specifically recognized by specific tumor proteases (MMP-2 and 9). The chimera tended to adopt a hairpin structure by electrostatic interaction between opposite charges and the shielding is released at target place, where the specific metalloproteinases are present [12].

The most frequent local trigger used for activation of smart nanocarriers designed for tumor targeting 
is the $\mathrm{pH}$, taking advantage of the acidic environment in the tumoral tissue. These strategies usually employ $\mathrm{pH}$-sensitive bonds such as hydrazone to couple a phospholipid to a long shielding polymer (PEG) and incorporate them to micelles or liposomes where the attached CPP is protected by steric hindrance provided by the PEG moiety. Release of protective PEG by pH-driven bond hydrolysis exposes CPP to cell membrane and allows cellular uptake [176]. Shielding can also be obtained by covalent amidization of lysines at the side chain amine with an acid-labile $\beta$-carboxylic amide. When the nanocarriers reach the tumor and accumulate there via the EPR effect, the acidic tumor environment hydrolyzes the amides and restores CPP functionality [177]. Histidines are natural pH sensors able to be protonated in the imidazole side chain when $\mathrm{pH}$ drops from the neutral physiological value $\left(\mathrm{pK}_{\mathrm{a}}=\right.$ 6.0). Then, the imidazole ring will be protonated in acidic environments such as tumoral milieu or endosomal/lysosomal subcellular compartments. Therefore, His residues may play a dual role: providing target selectivity for mild acidic tissue areas (extracellular) and enhancing endosome release when CPP uses an endocytic route for cell entrance (intracellular). The drop of $\mathrm{pH}$ along the endosome pathway is well characterized while decrease of $\mathrm{pH}$ in tumor areas may be less regular and difficult to predict. Some groups have demonstrated that, despite being low, the $\mathrm{pH}$ drop is a triggering factor for tumor control delivery of therapeutic molecules. The overall effect will depend on the $\mathrm{pH}$ drop (the lower the $\mathrm{pH}$ the higher the proportion of protonated histidine residues) as well as on the total number of histidine groups introduced in the carrier, allowing a certain level of external manipulation. Histidines can be introduced either within the CPP sequence to generate a dormant CPP, replacing positively charged Lys or Arg residues [178], or in the shielding partner, an anionic peptide that will weaken the protective electrostatic interaction when His residues become protonated at mild acidic environments [179]. Special interest has the use of long polyhistidines as protective polymers attached to the surface of nanocarriers in the so called 'pop-up' strategy [180]. CPPs anchored to poly-His are buried inside the protecting polymeric (PEG) corona and are rapidly exposed to the particle surface when the poly-His linker gets protonated.

Other target-place specific stimuli include high local concentrations of specific molecules, hypoxia or the mild hyperthermia found in damaged sites (tumors, infection and inflammatory areas). One example of elevated concentration in the target area is hyaluronidase, found in proliferative tumors to break the extracellular matrix. The anionic polysaccharide hyaluronic acid was used to cover the cationic CPP during transport. Rapid degradation of the protective shield by hyaluronidase at the target place switched on the CPP functionality and allowed proper delivery of the therapeutic payload [181]. A nice example of thermo-responsive elements are the elastin-like polypeptides (ELPs), structures that are soluble in monomeric form at $37^{\circ} \mathrm{C}$ but aggregate into nanoscale micelles above $42^{\circ} \mathrm{C}$. Fusion of an ELP with a CPP with weak permeation ability at monomeric structure, strongly improved the cell 
penetration capacity by increasing functional affinity (avidity) by heat-induced micelle formation at the target site [182]. The strategy has successfully been used for efficient delivery of therapeutic peptides and small molecules into tumors [183].

Stimuli triggering CPP activation and cargo release into the target cell can be external and therefore controlled by the therapist. An interesting example is the Antibody Targeted Triggered Electrically Modified Prodrug Type Strategy (ATTEMPTS) system, an adaptation of the Antibody Directed Enzyme Prodrug Therapy (ADEPT) concept to deliver macromolecular hydrophilic agents that require cell penetration helping activities (CPPs) to provide access to the cytosol. The system incorporates a targeting moiety comprising a cell target specific antibody linked to heparin and a CPP bound drug component. Both structures interact electrostatically between the anionic heparin and the cationic CPP to form a complex where the CPP stays dormant (prodrug), protected from protease degradation and for unspecific entrance in cells. The complex will accumulate at the targeting site by means of antibodyspecific binding. Once there, CPP masking can be reversed, triggered by the use of clinically approved strongly cationic protamine, recovering the cell permeability function and releasing the cargo (active drug) to the cytosol [184]. A great diversity of external triggering stimuli has been incorporated into the design of pharmaceutical carrier systems, generating an arsenal of tools to be checked for CPPmediated drug delivery. They include mostly physical methods such as temperature, light, ultrasound, electric and magnetic fields, osmotic pressure or radiofrequencies [185-187]. Some have been already evaluated on CPP-based systems [188]. Among these, the use of photolabile-caged CPPs stands out. They utilize light-cleavable protective groups, such as 6-nitroveratrylcarbonyl (Nvoc) or 1(bromomethyl)-4,5-dimethoxy-2-nitrobenzene, to temporarily cover and neutralize the positive charges of the CPP and later release them by controlled irradiation at the target site with UV light [189] or the more penetrative and less damaging near-infrared (NIR) light [190]. Light irradiation has also been used to release CPP from a protective covalent constraint state, obtained by alkylation of CPP on both edges and anchoring to a liposome surface, with one of the alkyl chain connected to the peptide by a UVscissile bond [191].

\section{Close to the end}

The number of possibilities to improve CPP stability is high and keeps on growing. However, only a few have been currently evaluated in clinical trials [6,14,192] and to our knowledge none have been registered by international agencies. Those assessed in clinical trials include natural unmodified CPPs such as Tat, R8 or p28 and modified CPPs that preserve peptide stability (Table 1). RT001 (Reverance Therapeutics) involved a reverse Tat sequence that improved transdermal delivery of cargo [82]. XG102 (Xigen) employed an all-D retro-inverso Tat sequence, a highly stable Tat analog [193]. AZX100 
(Capson Therapeutics) is based on PTD4, a Tat optimized sequence obtained by amino acid substitution [194]. Finally, AVI-5126 is built on R-Ahx-R repeats which utilizes 6-aminohexanoic acid spacers to provide protease resistance [14].

Table 1. Modified cell-penetrating peptides under clinical evaluation.

\begin{tabular}{|c|c|c|c|c|c|c|}
\hline Company & Product & CPP & Modification & Sequence & Cargo & Ref. \\
\hline $\begin{array}{l}\text { Sarepta } \\
\text { Therapeutics }\end{array}$ & $\begin{array}{l}\text { AVI- } \\
5126\end{array}$ & $\begin{array}{l}\text { R- } \\
\text { Ahx- } \\
R)_{4}\end{array}$ & $\begin{array}{l}\text { 6- } \\
\text { aminohexanoic } \\
\text { acid-spaced } \\
\text { oligo-arginine }\end{array}$ & $(\mathrm{R}-\mathrm{Ahx}-\mathrm{R})_{4}$ & $\begin{array}{l}\text { Antisense PMO } \\
\text { targeted to c- } \\
\text { Myc }\end{array}$ & {$[14]$} \\
\hline Xigen & XG-102 & ri-Tat & $\begin{array}{l}\text { Retroinverso } \\
\text { sequence }\end{array}$ & tdqsrpvqfInlttprkprpprrrqrrkkrg & $\begin{array}{l}\text { Selective JNK } \\
\text { inhibitor } \\
\text { peptide (D- } \\
\text { JNKI1) }\end{array}$ & {$[19 \$]$} \\
\hline $\begin{array}{l}\text { Revance } \\
\text { Therapeutics }\end{array}$ & RT001 & $\begin{array}{l}\text { Tat }_{57-} \\
49\end{array}$ & $\begin{array}{l}\text { Reverse Tat } \\
\text { sequence }\end{array}$ & RRRQRRKKR & Botulin toxin $\mathrm{A}$ & [82] \\
\hline $\begin{array}{l}\text { Capson } \\
\text { Therapeutics }\end{array}$ & AZX100 & PTD4 & $\begin{array}{l}\text { Optimized Tat } \\
\text { (amino acid } \\
\text { substitution) }\end{array}$ & YARAAARQARAWLRRASpAPLPGLK & $\begin{array}{l}\text { Phosphorylated } \\
\text { HSP20 peptide } \\
\text { analog }\end{array}$ & {$[194$} \\
\hline
\end{tabular}

\section{Conclusion}

Peptides are a growing and promising source of new medicines that can compensate the attrition observed with the classical small molecule based drugs. Among these biological alternatives, CPPs emerge as a potent tool as drug delivery system for both biological and chemical drugs. Taking advantage of the knowledge accumulated with therapeutic peptides, CPPs have been modified in order to improve their in vivo stability and bioavailability to fulfil the requirements to become a pharmaceutical product. The spectrum of possibilities to improve CPP stability is high, ranging from the simple conservative amino acid substitution to the sophisticated stimuli-response CPP activation strategies, and is expected to continue growing in the future. There are no general rules governing the impact of specific stabilization strategies in CPPs and every single modification has to be checked empirically for every individual case. However, this great variety of options is particularly interesting considering the 
diversity of applications, type of cargoes and routes of administration which impose specific requirements, increasing the value of these interesting delivering tools. A proper balance between peptide stability and biodegradability is crucial to ensure an accurate bioavailability and efficient cargo delivery while minimizing toxicity and unwanted side effects.

\section{Future perspective}

CPPs are very close to becoming a therapeutic reality as efficient biological drug delivery systems. While waiting for the most advanced trials to be successfully completed and for registration by the international agencies for use in clinical practice, new CPPs will start clinical evaluation. The foreseeable future may include improved versions of known CPPs with higher stability and efficiency as well as new properties such as target-cell specificity or controlled delivery of cargoes. In addition, fully novel CPPs may increase the overall diversity and help solving limitations found in older members of this family of biological shuttles. Rational design together with new searches from natural sources would provide new candidates for clinical evaluation. In this regard, marine organisms have been shown to be a promising source of bioactive peptides which have evolved under the selective pressure imposed by the harsh marine environmental conditions. Different post-translational modifications have been found in these organisms, some already evaluated to improve CPP stability (cystine knots, Damino acids.) and others, such as tryptophan bromidation or 3-methylisoleucine, are still to be tested in CPPs for their protease resistance properties [195]. Learning from these and other natural strategies, complemented with the development of new smart rational designs, will improve the chances to obtain optimal therapeutic CPPs. Meanwhile, efforts to understand the mechanisms of action of these molecular carriers, including bio-barriers penetration, membrane translocation, CPP-cargo complex organization and cargo release, will provide useful information for the design of a new generation of improved peptide-based molecular transporters. In addition, we should not forget that the complex CPP-cargo is the clinically relevant entity and there are a great diversity of cargoes transported by CPPs, from small chemical entities to sophisticated nanoparticles. Overall CPP stability is directly affected by the formation of the therapeutic complex (cargo and additional partners). Although a crucial step, optimization of CPP moeity may have a different impact on the overall complex stability on a caseby-case basis. Therefore, further development should be performed on each individual CPP-dependent medicine candidate in the preclinical development and for every specific therapeutic application.

\section{Executive summary}

\section{In vivo CPP degradation}

- $\quad$ Cell penetrating peptides (CPPs), as other regular peptides, suffer from a poor metabolic stability. They have specific residues particularly sensitive to protease degradation. 
Identification of these initial cleavage sites provides useful information to improve peptide stability.

- Degradation pattern depends on the biological environment: bio-barrier, tissue, cell, subcellular compartment and pathological status.

\section{Peptide stabilization by biological modification}

- Identification of specific protease-scissile sites allows to replace the sensitive residue and optimize CPP stability.

\section{Peptide stabilization by chemical modification}

- Appropriate chemical modification of the original CPP structure turns the molecule unrecognizable to proteases. Successful modifications include chiral isomerization, use of non-natural amino acids and substitution of peptide backbone with peptide bone surrogates.

\section{Conformational stabilization of CPPs}

- Strategies to stabilize a folded state by conformational restriction protect peptides from protease degradation. They comprise cyclization, disulfide formation and higher order structures such as miniature proteins, branched polymers and dendrimers.

\section{CPP shielding strategies}

- Physical shielding of CPPs prevents the access of proteolytic enzymes. Covering the peptide by polymer conjugation (PEGylation and similar modifications) or hiding the active moiety within complex structures protects CPP integrity and functionality while avoiding nonspecific cellular uptake. Stimuli-responsive control mechanisms allow site-specific CPP activation and cargo delivery.

\section{References}

Papers of special note have been highlighted as: • of interest; •• of considerable interest

1 Fawell S, Seery J, Daikh Y et al. Tat-mediated delivery of heterologous proteins into cells. Proc. Natl Acad. Sci. USA 91(2), 664-668 (1994).

2 Derossi D, Joliot $A H$, Chassaing G, Prochiantz A. The third helix of the Antennapedia homeodomain translocates through biological membranes. J. Biol. Chem. 269(14), 10444-10450 (1994).

3 Milletti F. Cell-penetrating peptides: classes, origin, and current landscape. Drug Discov. Today. 17(15-16), 850-860 (2012).

4 Koren E, Torchilin VP. Cell-penetrating peptides: breaking through to the other side. Trends Mol. Med. 18(7), 385-393 (2012). 
5 Bechara C, Sagan S. Cell-penetrating peptides: 20 years later, where do we stand? FEBS Lett. 587(12), 1693-1702 (2013).

6 Shi N-Q, Qi X-R, Xiang B, Zhang Y. A survey on "Trojan Horse" peptides: Opportunities, issues and controlled entry to "Troy." J. Control. Release 194, 53-70 (2014).

7 Reissmann S. Cell penetration: scope and limitations by the application of cell-penetrating peptides. J. Pept. Sci. 20(10), 760-784 (2014).

- Excellent and very comprehensive review covering the most important topics related with the application of cell penetrating peptides (CPPs).

8 Stalmans S, Wynendaele $\mathrm{E}$, Bracke $\mathrm{N}$ et al. Chemical-functional diversity in cell-penetrating peptides. PLoS ONE 8(8), e71752 (2013).

9 Jones AT, Sayers EJ. Cell entry of cell penetrating peptides: tales of tails wagging dogs. J. Control. Release 161(2), 582-591 (2012).

10 Choi YS, David AE . Cell penetrating peptides and the mechanisms for intracellular entry. Curr Pharm Biotechnol. 15(3), 192-199 (2014).

11 Munyendo WL, Lv H, Benza-Ingoula H, Baraza LD, Zhou J. Cell penetrating peptides in the delivery of biopharmaceuticals. Biomolecules 2(2), 187-202 (2012).

12 Macewan SR, Chilkoti A. Harnessing the power of cell-penetrating peptides: activatable carriers for targeting systemic delivery of cancer therapeutics and imaging agents. Wiley Interdiscip. Rev. Nanomed. Nanobiotechnol. 5(1), 31-48 (2013).

13 Johnson RM, Harrison SD, Maclean D. Therapeutic applications of cell-penetrating peptides. Methods Mol. Biol. 683, 535-551 (2011).

14 Vasconcelos L, Pärn K, Langel U. Therapeutic potential of cell-penetrating peptides. Ther. Deliv. 4(5), 573-591 (2013).

- Excellent review about the application of CPPs for the delivery of therapeutics in preclinical and clinical trials.

15 Rizzuti M, Nizzardo M, Zanetta C, Ramirez A, Corti S. Therapeutic applications of the cell penetrating HIV 1 Tat peptide. PubMed Commons. Drug Discov. Today. 20(1), 76-85 (2015).

16 Jiang Y, Li M, Zhang Z, Gong T, Sun X. Cell penetrating peptides as delivery enhancers for vaccine. Curr. Pharm. Biotechnol. 15(3), 256-266 (2014).

17 Hughes SR, Dowd PF, Johnson ET. Cell-penetrating recombinant peptides for potential use in agricultural pest control applications. Pharmaceuticals 5(10), 1054-1063 (2012).

18 Chuah J-A, Yoshizumi T, Kodama Y, Numata K. Gene introduction into the mitochondria of Arabidopsis thaliana via peptide-based carriers. Sci. Rep. 5, 7751 (2015).

19 Johnson LN, Cashman SM, Kumar-Singh R. Cell-penetrating peptide for enhanced delivery of nucleic acids and drugs to ocular tissues including retina and cornea. Mol. Ther. 16(1), 107-114 (2008).

20 Liu C, Tai L, Zhang W, Wei G, Pan W, Lu W. Penetratin, a potentially powerful absorption enhancer for noninvasive intraocular drug delivery. Mol. Pharm. 11(4), 1218-1227 (2014).

21 Desai P, Patlolla RR, Singh M. Interaction of nanoparticles and cell-penetrating peptides with skin for transdermal drug delivery. Mol. Membr. Biol. 27(7), 247-259 (2010).

22 Kamei N, Morishita M, Ehara J, Takayama K. Permeation characteristics of oligoarginine through intestinal epithelium and its usefulness for intestinal peptide drug delivery. J. Control. Release 131(2), 94-99 (2008).

23 Kumar S, Zakrewsky M, Chen M, Menegatti S, Ja M, Mitragotri S. Peptides as skin penetration enhancers: mechanisms of action. J. Control Release. 199, 168-178 (2015). 
24 Khafagy ES, Morishita M, Isowa K, Imai J, Takayama K. Effect of cell-penetrating peptides on the nasal absorption of insulin. J. Control. Release 133(2), 103-108 (2009).

25 Liu $\mathrm{H}$, Zhang W, Ma L et al. The improved blood-brain barrier permeability of endomorphin-1 using the cellpenetrating peptide synB3 with three different linkages. Int. J. Pharm. 476(1-2), 1-8 (2014).

26 Kanazawa T, Morisaki K, Suzuki S, Takashima Y. Prolongation of life in rats with malignant glioma by intranasal siRNA/drug codelivery to the brain with cell-penetrating peptide-modified micelles. Mol. Pharm. 11(5), 1471-1478 (2014).

27 Kamei N, Takeda-Morishita M. Brain delivery of insulin boosted by intranasal coadministration with cell penetrating peptides. J. Control Release. 197, 105-110 (2015).

28 Ezzat K, Zaghloul EM, El Andaloussi S et al. Solid formulation of cell-penetrating peptide nanocomplexes with siRNA and their stability in simulated gastric conditions. J. Control. Release 162(1), 1-8 (2012).

29 Khafagy ES, Morishita M. Oral biodrug delivery using cell-penetrating peptide. Adv. Drug Deliv. Rev. 64(6), 531-539 (2012).

30 Kristensen M, Foged C, Berthelsen J, Nielsen HM. Peptide-enhanced oral delivery of therapeutic peptides and proteins. J. Drug Del. Sci. Tech. 23(4), 365-373 (2013).

31 Nielsen EJB, Yoshida S, Kamei $\mathrm{N}$ et al. In vivo proof of concept of oral insulin delivery based on a coadministration strategy with the cell-penetrating peptide penetratin. J. Control. Release 189, 19-24 (2014).

-. In vivo demonstration of how a protease resistant D form CPP enhances insulin absorption by oral administration.

32 Fais S, Venturi G, Gatenbi B. Microenvironmental acidosis in carcinogenesis and metastases: new strategies in prevention and therapy. Cancer Metastasis Rev. 33(4), 1095-1108 (2014).

33 Jobin ML, Alves ID. On the importance of electrostatic interactions between cell penetrating peptides and membranes: a pathway toward tumor cell selectivity? Biochimie 107(Pt A), 154-159 (2014).

34 Nakamura $\mathrm{H}$, Jun F, Maeda $\mathrm{H}$. Development of next-generation macromolecular drugs based on the EPR effect: challenges and pitfalls. Expert Opin. Drug. Deliv. 12(1), 53-64 (2015).

35 Shin MC, Zhang J, Min KA et al. Cell-penetrating peptides: achievements and challenges in application for cancer treatment. J. Biomed. Mater. Res. Part A. 102(2), 575-587 (2014).

36 Martín I, Teixidó M, Giralt E. Building cell selectivity into CPP-mediated strategies. Pharmaceuticals 3(5), 1456-1490 (2010).

37 Kondo E, Saito K, Tashiro Y et al. Tumour lineage-homing cell-penetrating peptides as anticancer molecular delivery systems. Nat. Commun. 3, 951 (2012).

38 Violand B, Siegel N. Protein and peptide chemical and physical stability. In: Peptide and Protein Drug Analysis. Reid R (Ed.). CRC Press, 257-283 (1999).

39 Swain S, Mondal D, Beg S et al. Stabilization and delivery approaches for protein and peptide pharmaceuticals: an extensive review of patents. Recent Pat. Biotechnol. 7(1), 28-46 (2013).

40 Elmquist A, Langel U. In vitro uptake and stability study of pVEC and its all-D analog. Biol. Chem. 384(3), 387-393 (2003).

41 Lindgren ME, Hällbrink MM, Elmquist AM, Langel U. Passage of cell-penetrating peptides across a human epithelial cell layer in vitro. Biochem. J. 377(Pt 1), 69-76 (2004).

42 Pooga M, Hällbrink M, Zorko M, Langel U. Cell penetration by transportan. FASEB J. 12(1), 67-77 (1998).

43 Tréhin R, Nielsen HM, Jahnke H-G, Krauss U, Beck-Sickinger AG, Merkle HP. Metabolic cleavage of cellpenetrating peptides in contact with epithelial models: human calcitonin (hCT)-derived peptides, Tat(47-57) and penetratin(43-58). Biochem. J. 382(Pt 3), 945-956 (2004). 
•• The first in-depth in vitro metabolism study for CPPs using different cell culture models.

44 Foerg $\mathrm{C}$, Weller $\mathrm{KM}$, Rechsteiner $\mathrm{H}$ et al. Metabolic cleavage and translocation efficiency of selected cell penetrating peptides: a comparative study with epithelial cell cultures. AAPS J. 10(2), 349-359 (2008).

45 Peng J, Zu L, Fang W, Huang L, Wang Y, He D. Selective cleavage of protonated penetratin and its substitutes under low-energy collision-induced dissociation condition. J. Mass Spectrom. 45(6), 627-634 (2010).

46 Tikhonov I, Ruckwardt TJ, Berg S, Hatfield GS, Pauza CD. Furin cleavage of the HIV-1 Tat protein. FEBS Lett. 565(1-3), 89-92 (2004).

47 Grunwald J, Rejtar T, Sawant R, Wang Z, Torchilin VP. TAT peptide and its conjugates: proteolytic stability. Bioconjug. Chem. 20(8), 1531-1537 (2009).

48 Guergnon J, Dessauge F, Dominguez V et al. Use of penetrating peptides interacting with PP1/PP2A proteins as a general approach for a drug phosphatase technology. Mol. Pharmacol. 69(4), 1115-1124 (2006).

49 Arrouss I, Nemati F, Roncal F et al. Specific targeting of Caspase-9/PP2A interaction as potential new anticancer therapy. PLoS ONE 8(4) (2013).

50 Fominaya J, Bravo J, Decaudin D, Brossa JY, Nemati F, Rebollo A. Enhanced serum proteolysis resistance of cell-penetrating peptides. Ther. Deliv. 6(2), 139-147 (2015).

51 Lindgren M, Rosenthal-Aizman K, Saar K et al. Overcoming methotrexate resistance in breast cancer tumour cells by the use of a new cell-penetrating peptide. Biochem. Pharmacol. 71(4), 416-425 (2006).

52 Aroui S, Brahim S, Waard MD, Kenani A. Cytotoxicity, intracellular distribution and uptake of doxorubicin and doxorubicin coupled to cell-penetrating peptides in different cell lines: a comparative study. Biochem. Biophys. Res. Commun. 391(1), 419-425 (2010).

53 Palm C, Jayamanne M, Kjellander M, Hällbrink M. Peptide degradation is a critical determinant for cellpenetrating peptide uptake. Biochim. Biophys. Acta Biomembr. 1768(7), 1769-1776 (2007).

- The first comparative study between extra and intracellular degradation kinetics of CPPs. It allowed the identification of specific proteases and the development of a kinetic model.

54 Fischer R, Hufnagel $\mathrm{H}$, Brock R. A doubly labeled penetratin analogue as a ratiometric sensor for intracellular proteolytic stability. Bioconjug. Chem. 21(1), 64-73 (2010).

55 Wadhwani P, Epand RF, Heidenreich N, Bürck J, Ulrich AS, Epand RM. Membrane-active peptides and the clustering of anionic lipids. Biophys. J. 103(2), 265-274 (2012).

56 Yang ST, Zaitseva E, Chernomordik LV, Melikov K. Cell-penetrating peptide induces leaky fusion of liposomes containing late endosome-specific anionic lipid. Biophys. J. 99(8), 2525-2533 (2010).

57 Madani F, Abdo R, Lindberg $S$ et al. Modeling the endosomal escape of cell-penetrating peptides using a transmembrane pH gradient. Biochim. Biophys. Acta - Biomembr. 1828(4), 1198-1204 (2013).

58 Frankel AD, Pabo CO. Cellular uptake of the tat protein from human immunodeficiency virus. Cell $55(6)$, 1189-1193 (1988).

59 Lo SL, Wang S. An endosomolytic Tat peptide produced by incorporation of histidine and cysteine residues as a nonviral vector for DNA transfection. Biomaterials 29(15), 2408-2414 (2008).

60 Lee YJ, Johnson G, Pellois JP. Modeling of the endosomolytic activity of HA2-TAT peptides with red blood cells and ghosts. Biochemistry 49(36), 7854-7866 (2010).

61 Shete HK, Prabhu RH, Patravale VB. Endosomal escape: a bottleneck in intracellular delivery. J. Nanosci. Nanotechnol. 14(1), 460-474 (2014).

62 Liou J, Liu B, Martin A, Huang Y, Chiang H, Lee H. Protein transduction in human cells is enhanced by cell- 
penetrating peptides fused with an endosomolytic HA2 sequence. Peptides 37(2), 273-284 (2012).

63 Mohammed AF, Abdul-Wahid A, Huang EHB et al. The Pseudomonas aeruginosa exotoxin A translocation domain facilitates the routing of CPP-protein cargos to the cytosol of eukaryotic cells. J. Control. Release 164(1), 58-64 (2012).

64 Gramlich PA, Remington MP, Amin J, Betenbaugh MJ, Fishman PS. Tat-tetanus toxin fragment C: a novel protein delivery vector and its use with photochemical internalization. J. Drug Target. 21(7), 662-674 (2013).

65 Lundberg $\mathrm{P}$, El-Andaloussi S, Sütlü $\mathrm{T}$, Johansson $\mathrm{H}$, Langel U. Delivery of short interfering RNA using endosomolytic cell-penetrating peptides. FASEB J. 21(11), 2664-2671 (2007).

66 El Andaloussi S, Lehto T, Mäger I et al. Design of a peptide-based vector, PepFect6, for efficient delivery of siRNA in cell culture and systemically in vivo. Nucleic Acids Res. 39(9), 3972-3987 (2011).

67 Erazo-Oliveras A, Muthukrishnan N, Baker R, Wang TY, Pellois JP. Improving the endosomal escape of cellpenetrating peptides and their cargos: strategies and challenges. Pharmaceuticals 5(11), 1177-1209 (2012).

68 Vlieghe P, Lisowski V, Martinez J, Khrestchatisky M. Synthetic therapeutic peptides: science and market. Drug Discov. Today 15(1-2), 40-56 (2010).

69 Goodwin D, Simerska P, Toth I. Peptides as therapeutics with enhanced bioactivity. Curr. Med. Chem. 19(26), 4451-4461 (2012).

$70 \mathrm{Kim} \mathrm{H}$, Jang JH, Kim SC, Cho JH. De novo generation of short antimicrobial peptides with enhanced stability and cell specificity. J. Antimicrob. Chemother. 69(1), 121-132 (2014).

71 Bobone S, Piazzon A, Orioni B et al. The thin line between cell penetrating and antimicrobial peptides: the case of Pep 1 and Pep 1 K. J. Pept. Sci. 17(5), 335-341 (2011).

72 Rodriguez Plaza JG, Morales-Nava R, Diener C et al. Cell penetrating peptides and cationic antibacterial peptides: two sides of the same coin. J. Biol. Chem. 289(21), 14448-14457 (2014).

73 Ji S, Li W, Zhang L, Zhang Y, Cao B. Cecropin A melittin mutant with improved proteolytic stability and enhanced antimicrobial activity against bacteria and fungi associated with gastroenteritis in vitro. Biochem. Biophys. Res. Commun. 451(4), 650-655 (2014).

74 Sharma A, Singla D, Rashid M, Raghava GP. Designing of peptides with desired half-life in intestine-like environment. BMC Bioinformatics 15(1), 282 (2014).

75 Rennert R, Neundorf I, Beck-Sickinger AG. Calcitonin-derived peptide carriers: mechanisms and application. Adv. Drug Deliv. Rev. 60(4-5), 485-498 (2008).

76 Rennert R, Wespe C, Beck-Sickinger AG, Neundorf I. Developing novel hCT derived cell-penetrating peptides with improved metabolic stability. Biochim. Biophys. Acta - Biomembr. 1758(3), 347-354 (2006).

77 Persson D, Thorén PEG, Lincoln P, Nordén B. Vesicle membrane interactions of penetratin analogues. Biochemistry 43(34), 11045-11055 (2004).

78 Bahnsen JS, Franzyk H, Sandberg-Schaal A, Nielsen HM. Antimicrobial and cell-penetrating properties of penetratin analogs: effect of sequence and secondary structure. Biochim. Biophys. Acta - Biomembr. 1828(2), 223-232 (2013).

79 Khafagy ES, Morishita M, Ida N, Nishio R, Isowa K, Takayama K. Structural requirements of penetratin absorption enhancement efficiency for insulin delivery. J. Control. Release 143(3), 302-310 (2010).

80 Ivanova GD, Arzumanov A, Abes $\mathrm{R}$ et al. Improved cell-penetrating peptide-PNA conjugates for splicing redirection in HeLa cells and exon skipping in mdx mouse muscle. Nucleic Acids Res. 36(20), 6418-6428 (2008).

81 Ho A, Schwarze SR, Mermelstein SJ, Waksman G, Dowdy SF. Synthetic protein transduction domains: enhanced transduction potential in vitro and in vivo. Cancer Res. 61(2), 474-477 (2001). 
82 Howl J, Jones S. Transport molecules using reverse sequence HIV-Tat polypeptides: not just any old Tat? (WO200808225). Expert Opin. Ther. Pat. 19(9), 1329-1333 (2009).

83 Muppidi A, Doi K, Edwardraja S et al. Rational design of proteolytically stable, cell-permeable peptide-based selective Mcl-1 inhibitors. J. Am. Chem. Soc. 134(36), 14734-14737 (2012).

84 Rodríguez V, Asenjo JA, Andrews BA. Design and implementation of a high yield production system for recombinant expression of peptides. Microb. Cell Fact. 13, 65-75 (2014).

85 Rodríguez V, Lascani J, Asenjo JA, Andrews BA. Production of cell penetrating peptides in Escherichia coli using an intein mediated system. Appl. Biochem. Biotechnol. 175(6), 3025-3037 (2015).

86 Gentilucci L, De Marco R, Cerisoli L. Chemical modifications designed to improve peptide stability: incorporation of non-natural amino acids, pseudo-peptide bonds, and cyclization. Curr. Pharm. Des. 16(28), 3185-3203 (2010).

- A comprehensive and detailed review about chemical modifications of peptides to improve stability.

87 Jung HJ, Jeong KS, Lee DG. Effective antibacterial action of Tat (47-58) by increased uptake into bacterial cells in the presence of trypsin. J. Microbiol. Biotechnol. 18(5), 990-996 (2008).

88 Nielsen EJ, Kamei N, Takeda-morishita M. Safety of the cell-penetrating peptide penetratin as an oral absorption enhancer. Biol. Pharm. Bull. 38(1), 144-146 (2015).

89 Pujals S, Fernández-Carneado J, Ludevid MD, Giralt E. D-SAP: a new, noncytotoxic, and fully protease resistant cell-penetrating peptide. ChemMedChem 3(2), 296-301 (2008).

90 Pujals S, Sabidó E, Tarragó T, Giralt E. all-D proline-rich cell-penetrating peptides: a preliminary in vivo internalization study. Biochem. Soc. Trans. 35(Pt 4), 794-796 (2007).

91 Tünnemann G, Ter-Avetisyan G, Martin RM, Stöckl M, Herrmann A, Cardoso MC. Live-cell analysis of cell penetration ability and toxicity of oligo-arginines. J. Pept. Sci. 14(4), 469-476 (2008).

92 Rothbard JB, Garlington S, Lin Q et al. Conjugation of arginine oligomers to cyclosporin A facilitates topical delivery and inhibition of inflammation. Nat. Med. 6(11), 1253-1257 (2000).

93 Purkayastha N, Eyer K, Robinson T, Dittrich PS, Beck AK, Seebach D. Enantiomeric and diastereoisomeric (mixed) L/D -octaarginine derivatives - a simple way of modulating the properties of cell-penetrating peptides. Chem. Biodivers. 10(7), 1165-1184 (2013).

94 Zhang X, Jin Y, Plummer MR, Pooyan S, Gunaseelan S, Sinko PJ. Endocytosis and membrane potential are required for HeLa cell uptake of R.I.-CKTat9, a retro-inverso tat cell penetrating peptide. Mol. Pharm. 6(3), 836-848 (2009).

95 Holm T, Räägel H, Andaloussi S El et al. Retro-inversion of certain cell-penetrating peptides causes severe cellular toxicity. Biochim. Biophys. Acta - Biomembr. 1808(6), 1544-1551 (2011).

96 Jones S, Howl J. Enantiomer-specific bioactivities of peptidomimetic analogues of mastoparan and mitoparan: characterization of inverso mastoparan as a highly efficient cell penetrating peptide. Bioconjug. Chem. 23(1), 47-56 (2012).

97 Montrose K, Yang Y, Krissansen GW. X-pep, a novel cell-penetrating peptide motif derived from the hepatitis $B$ virus. Biochem. Biophys. Res. Commun. 453(1), 64-68 (2014).

98 Prades R, Oller-Salvia B, Schwarzmaier SM et al. Applying the retro-enantio approach to obtain a peptide capable of overcoming the blood-brain barrier. Angew. Chemie Int. Ed. 54(13), 3967-3972 (2015).

.. Interesting application of the retro-enantio approach to develop a BBB-specific CPP.

99 Warso MA, Richards JM, Mehta D et al. A first-in-class, first-in-human, phase I trial of p28, a non-HDM2mediated peptide inhibitor of p53 ubiquitination in patients with advanced solid tumours. Br. J. Cancer. 108(5), 1061-70 (2013). 
100 Yamada T, Signorelli S, Cannistraro S, Beattie CW, Bizzarri AR. Chirality switching within an anionic cellpenetrating peptide inhibits translocation without affecting preferential entry. Mol. Pharm. 12(1), 140-149 (2015).

101 Verdurmen WPR, Bovee-Geurts PH, Wadhwani P et al. Preferential uptake of L-versus D-amino acid cellpenetrating peptides in a cell type-dependent manner. Chem. Biol. 18(8), 1000-1010 (2011).

102 Lyu PC, Sherman JC, Chen A, Kallenbach NR. Alpha-helix stabilization by natural and unnatural amino acids with alkyl side chains. Proc. Natl Acad. Sci. USA 88(12), 5317-5320 (1991).

103 Jones S, Howl J. Charge delocalisation and the design of novel mastoparan analogues: enhanced cytotoxicity and secretory efficacy of [Lys5, Lys 8, Aib10]MP. Regul. Pept. 121(1-3), 121-128 (2004).

104 Kato T, Oba M, Nishida K, Tanaka M. Cell-penetrating helical peptides having l-arginines and five-membered ring a, $\alpha$-disubstituted $\alpha$-amino acids. Bioconjug. Chem. 25(10), 1761-1768 (2014).

105 Chen F, Ma B, Yang Z-C, Lin G, Yang D. Extraordinary metabolic stability of peptides containing alphaaminoxy acids. Amino Acids. 43(1), 499-503 (2012).

106 Ma Y, Yang D, Ma Y, Zhang YH. Novel cell-penetrating peptides based on a-aminoxy acids. ChemBioChem. 13(1), 73-79 (2012).

107 Potocky TB, Menon AK, Gellman SH. Effects of conformational stability and geometry of guanidinium display on cell entry by beta-peptides. J. Am. Chem. Soc. 127(11), 3686-3687 (2005).

108 Youngblood DS, Hatlevig SA, Hassinger JN, Iversen PL, Moulton HM. Stability of cell-penetrating peptidemorpholino oligomer conjugates in human serum and in cells. Bioconjug. Chem. 18(1), 50-60 (2007).

109 Foged C, Franzyk H, Bahrami S et al. Cellular uptake and membrane-destabilising properties of alphapeptide/beta-peptoid chimeras: lessons for the design of new cell-penetrating peptides. Biochim. Biophys. Acta - Biomembr. 1778(11), 2487-2495 (2008).

110 Farrera-Sinfreu J, Giralt E, Castel S, Albericio F, Royo M. Cell-penetrating cis-gamma-amino-I-prolinederived peptides. J. Am. Chem. Soc. 127(26), 9459-9468 (2005).

111 Beck JG, Chatterjee J, Laufer B et al. Intestinal permeability of cyclic peptides: common key backbone motifs identified. J. Am. Chem. Soc. 134(29), 12125-12133 (2012).

112 Murphy JE, Uno T, Hamer JD, Cohen FE, Dwarki V, Zuckermann RN. A combinatorial approach to the discovery of efficient cationic peptoid reagents for gene delivery. Proc. Natl Acad. Sci. USA 95(4), 1517-1522 (1998).

113 Wender PA, Mitchell DJ, Pattabiraman K, Pelkey ET, Steinman L, Rothbard JB. The design, synthesis, and evaluation of molecules that enable or enhance cellular uptake: peptoid molecular transporters. Proc. Natl Acad. Sci. USA 97(24), 13003-13008 (2000).

114 Kölmel DK, Fürniss D, Susanto S et al. Cell penetrating peptoids (CPPos): synthesis of a small combinatorial library by using IRORI MiniKans. Pharmaceuticals 5(12), 1265-1281 (2012).

115 Huang W, Seo J, Lin JS, Barron AE. Peptoid transporters: effects of cationic, amphipathic structure on their cellular uptake. Mol. Biosyst. 8(10), 2626-2628 (2012).

116 Kölmel DK, Hörner A, Rönicke F, Nieger M, Schepers U, Bräse S. Cell-penetrating peptoids: introduction of novel cationic side chains. Eur. J. Med. Chem. 79, 231-243 (2014).

117 Fridkin G, Gilon C, Gilon T, Loyter A. Systematic solid-phase synthesis of linear pseudooligolysines containing multiple adjacent $\mathrm{CH}(2) \mathrm{NH}$ amide bond surrogates: potential agents for gene delivery. J. Pept. Res. 58(1), 36-44 (2001).

118 Su Y, Doherty T, Waring AJ, Ruchala P, Hong M. Roles of arginine and lysine residues in the translocation of a cell-penetrating peptide from13C, 31P, and ${ }^{19} \mathrm{~F}$ solid-state NMR. Biochemistry 48(21), 4587-4595 (2009).

119 Åmand HL, Rydberg HA, Fornander LH, Lincoln P, Nordén B, Esbjörner EK. Cell surface binding and uptake 
of arginine- and lysine-rich penetratin peptides in absence and presence of proteoglycans. Biochim. Biophys. Acta - Biomembr. 1818(11), 2669-2678 (2012).

120 Stanzl EG, Trantow BM, Vargas JR, Wender PA. Fifteen years of cell-penetrating, guanidinium-rich molecular transporters: basic science, research tools, and clinical applications. Acc. Chem. Res. 46(12), 2944-2954 (2013).

121 Rothbard JB, Kreider E, VanDeusen CL, Wright L, Wylie BL, Wender PA. Arginine-rich molecular transporters for drug delivery: role of backbone spacing in cellular uptake. J. Med. Chem. 45(17), 3612-3618 (2002).

122 Patil KM, Naik RJ, Vij M et al. Second generation, arginine-rich (R-X'-R)4-type cell-penetrating $\alpha-\omega-\alpha-$ peptides with constrained, chiral $\omega$-amino acids $\left(X^{\prime}\right)$ for enhanced cargo delivery into cells. Bioorganic Med. Chem. Lett. 24(17), 4198-4202 (2014).

123 Patil KM, Naik RJ, Rajpal, , Fernandes M, Ganguli M, Kumar VA. Highly efficient (R-X-R)-type carbamates as molecular transporters for cellular delivery. J. Am. Chem. Soc. 134(17), 7196-7199 (2012).

124 Bock JE, Gavenonis J, Kritzer JA. Getting in shape: controlling peptide bioactivity and bioavailability using conformational constraints. ACS Chem. Biol. 8(3), 488-499 (2013).

125 Dharanipragada R. New modalities in conformationally constrained peptides for potency, selectivity and cell permeation. Future Med. Chem. 5(7), 831-849 (2013).

126 Lättig-Tünnemann G, Prinz M, Hoffmann D et al. Backbone rigidity and static presentation of guanidinium groups increases cellular uptake of arginine-rich cell-penetrating peptides. Nat. Commun. 2, 453 (2011).

127 Nischan N, Herce HD, Natale F et al. Covalent attachment of cyclic TAT peptides to GFP results in protein delivery into live cells with immediate bioavailability. Angew. Chemie Int. Ed. 54(6), 1950-1953 (2015).

128 Qian Z, Liu T, Liu YY et al. Efficient delivery of cyclic peptides into mammalian cells with short sequence motifs. ACS Chem. Biol. 8(2), 423-431 (2013).

129 Qian Z, Larochelle JR, Jiang B et al. Early endosomal escape of a cyclic cell-penetrating peptide allows effective cytosolic cargo delivery. Biochemistry. 53(24), 4034-4046 (2014).

130 Lian W, Jiang B, Qian Z, Pei D. Cell-permeable bicyclic peptide inhibitors against intracellular proteins. J. Am. Chem. Soc. 136(28), 9830-9833 (2014).

131 Craik DJ, Swedberg JE, Mylne JS, Cemazar M. Cyclotides as a basis for drug design. Expert Opin. Drug Discov. 7(3), 179-194 (2012).

132 Cascales L, Henriques ST, Kerr MC et al. Identification and characterization of a new family of cellpenetrating peptides: cyclic cell-penetrating peptides. J. Biol. Chem. 286(42), 36932-36943 (2011).

$133 \mathrm{Ji} \mathrm{Y,} \mathrm{Majumder} \mathrm{S,} \mathrm{Millard} \mathrm{M} \mathrm{et} \mathrm{al.} \mathrm{In} \mathrm{vivo} \mathrm{activation} \mathrm{of} \mathrm{the} \mathrm{p53} \mathrm{tumor} \mathrm{suppressor} \mathrm{pathway} \mathrm{by} \mathrm{an} \mathrm{engineered}$ cyclotide. J. Am. Chem. Soc. 135(31), 11623-11633 (2013).

134 D'Souza C, Henriques ST, Wang CK, Craik DJ. Structural parameters modulating the cellular uptake of disulfide-rich cyclic cell-penetrating peptides: MCoTI-II and SFTI-1. Eur. J. Med. Chem. 88, 10-18 (2014).

135 Huang YH, Chaousis S, Cheneval O, Craik DJ, Henriques ST. Optimization of the cyclotide framework to improve cell penetration properties. Front. Pharmacol. 6, 1-7 (2015).

136 Schafmeister CE, Po J, Verdine GL. An all-hydrocarbon cross-linking system for enhancing the helicity and metabolic stability of peptides. J. Am. Chem. Soc. 122(24), 5891-5892 (2000).

137 Verdine GL, Hilinski GJ. Stapled peptides for intracellular drug targets. Methods Enzymol. 503, 3-33 (2012).

138 Walensky LD, Bird GH. Hydrocarbon-stapled peptides: principles, practice, and progress. J. Med. Chem. 57(15), 6275-6288 (2014).

139 Giordanetto F, Revell JD, Knerr L et al. Stapled vasoactive intestinal peptide (VIP) derivatives improve 
VPAC2 agonism and glucose-dependent insulin secretion. ACS Med. Chem. Lett. 4(12), 1163-1168 (2013).

140 Sun TL, Sun Y, Lee CC, Huang HW. Membrane permeability of hydrocarbon-cross-linked peptides. Biophys. J. 104(9), 1923-1932 (2013).

141 Muppidi A, Li X, Chen J, Lin Q. Conjugation of spermine enhances cellular uptake of the stapled peptidebased inhibitors of p53-Mdm2 interaction. Bioorganic Med. Chem. Lett. 21(24), 7412-7415 (2011).

$142 \mathrm{Li}$ Y, Tang L, Gong M. Developments of glucagon like peptide-1 (GLP-1) and long-acting ana- logs in clinical and preclinical studies for treatment of Type 2 diabetes. Curr. Pharm. Biotechnol. 14(9), 835-841 (2013).

143 Lee S-J, Yoon SH, Doh KO. Enhancement of gene delivery using novel homodimeric tat peptide formed by disulfide bond. J. Microbiol. Biotechnol. 21(8), 802-807 (2011).

144 Åmand HL, Nordén B, Fant K. Functionalization with C-terminal cysteine enhances transfection efficiency of cell-penetrating peptides through dimer formation. Biochem. Biophys. Res. Commun. 418(3), 469-474 (2012).

145 Farkhani SM, Valizadeh A, Karami H, Mohammadi S, Sohrabi N, Badrzadeh F. Cell penetrating peptides: efficient vectors for delivery of nanoparticles, nanocarriers, therapeutic and diagnostic molecules. Peptides 57, 78-94 (2014).

- Nice review covering applications of CPPs for nanoparticle delivery a growing and promising field.

146 Chakrabarti A, Witsenburg JJ, Sinzinger MD et al. Multivalent presentation of the cell-penetrating peptide nona-arginine on a linear scaffold strongly increases its membrane-perturbing capacity. Biochim. Biophys. Acta 1838(12), 1-10 (2014).

147 Blum AP, Kammeyer JK, Yin J et al. Peptides displayed as high density brush polymers resist proteolysis and retain bioactivity. J. Am. Chem. Soc. 136(43), 15422-15437 (2014).

148 Krauss U, Müller M, Stahl M, Beck-Sickinger AG. In vitro gene delivery by a novel human calcitonin (hCT)derived carrier peptide. Bioorganic Med. Chem. Lett. 14(1), 51-54 (2004).

149 Eggimann GA, Blattes E, Buschor S et al. Designed cell penetrating peptide dendrimers efficiently internalize cargo into cells. Chem. Commun. (Camb.) 50(55), 7254-7257 (2014).

150 Saleh AF, Arzumanov A, Abes R, Owen D, Lebleu B, Gait MJ. Synthesis and splice-redirecting activity of branched, arginine-rich peptide dendrimer conjugates of peptide nucleic acid oligonucleotides. Bioconjug. Chem. 21(10), 1902-1911 (2010).

151 Bonduelle CV, Gillies ER. Dendritic guanidines as efficient analogues of cell penetrating peptides. Pharmaceuticals 3(3), 636-666 (2010).

152 Won Y-W, Kim HA, Lee M, Kim Y-H. Reducible poly(oligo-D-arginine) for enhanced gene expression in mouse lung by intratracheal injection. Mol. Ther. 18(4), 734-742 (2010).

153 Pujals S, Giralt E. Proline-rich, amphipathic cell-penetrating peptides. Adv. Drug Deliv. Rev. 60(4-5), 473-484 (2008).

154 Sanclimens G, Shen H, Giralt E, Albericio F, Saltzman MW, Royo M. Synthesis and screening of a small library of proline-based biodendrimers for use as delivery agents. Biopolym. - Pept. Sci. Sect. 80(6), 800-814 (2005).

155 Ackerman SE, Currier NV, Bergen JM, Cochran JR. Cystine-knot peptides: emerging tools for cancer imaging and therapy. Expert Rev. Proteomics. 11(5), 561-572 (2014).

156 Daniels DS, Schepartz A. Intrinsically cell-permeable miniature proteins based on a minimal cationic PPII motif. J. Am. Chem. Soc. 129(47), 14578-14579 (2007).

157 Smith BA, Daniels DS, Coplin AE, Jordan GE, McGregor LM, Schepartz A. Minimally cationic cell-permeable miniature proteins via $\alpha$-helical arginine display. J. Am. Chem. Soc. 130(10), 2948-2949 (2008). 
158 Kimura RH, Teed R, Hackel BJ et al. Pharmacokinetically stabilized cystine knot peptides that bind Alpha-vBeta-6 integrin with single-digit nanomolar affinities for detection of pancreatic cancer. Clin. Cancer Res. 18(3), 839-849 (2012).

159 Lehto T, Simonson OE, Mäger I et al. A peptide-based vector for efficient gene transfer in vitro and in vivo. Mol. Ther. 19(8), 1457-1467 (2011).

160 Youn P, Chen Y, Furgeson DY. A myristoylated cell-penetrating peptide bearing a transferrin receptortargeting sequence for neuro-targeted siRNA delivery. Mol. Pharm. 11(2), 486-495 (2014).

161 Lee JS, Tung $\mathrm{CH}$. Lipo-oligoarginines as effective delivery vectors to promote cellular uptake. Mol. Biosyst. 6(10), 2049-2055 (2010).

162 Lee JS, Tung $\mathrm{CH}$. Enhanced cellular uptake and metabolic stability of lipo-oligoarginine peptides. Biopolymers. 96(6), 772-779 (2011).

163 Zhang P, Cheetham AG, Lin YA, Cui H. Self-assembled tat nanofibers as effective drug carrier and transporter. ACS Nano. 7(7), 5965-5977 (2013).

164 Yoon Y-R, Lim Y, Lee E, Lee M. Self-assembly of a peptide rod-coil: a polyproline rod and a cell-penetrating peptide Tat coil. Chem. Commun. (Camb.) 16, 1892-1894 (2008).

165 Lim YB, Lee E, Lee M. Cell-penetrating-peptide-coated nanoribbons for intracellular nanocarriers. Angew. Chemie - Int. Ed. 46(19), 3475-3478 (2007).

166 Shinde A, Feher KM, Hu C, Slowinska K. Peptide internalization enabled by folding: triple helical cellpenetrating peptides. J. Pept. Sci. 21(2), 77-84 (2015).

167 Mandal D, Nasrolahi Shirazi A, Parang K. Self-assembly of peptides to nanostructures. Org. Biomol. Chem. 12(22), 3544-3561 (2014).

168 Pujals S, Fernández-Carneado J, López-Iglesias C, Kogan MJ, Giralt E. Mechanistic aspects of CPPmediated intracellular drug delivery: relevance of CPP self-assembly. Biochim. Biophys. Acta - Biomembr. 1758(3), 264-279 (2006).

169 Fominaya J, Gasset M, García R, Roncal F, Albar JP, Bernard A. An optimized amphiphilic cationic peptide as an efficient non-viral gene delivery vector. J. Gene Med. 2(6), 455-464 (2000).

170 Jafari M, Xu W, Pan R, Sweeting CM, Karunaratne DN, Chen P. Serum stability and physicochemical characterization of a novel amphipathic peptide C6M1 for siRNA delivery. PLoS ONE 9(5), 1-9 (2014).

171 Rydström A, Deshayes S, Konate $\mathrm{K}$ et al. Direct translocation as major cellular uptake for CADY selfassembling peptide-based nanoparticles. PLoS ONE 6(10) (2011).

172 Konate K, Rydstrom A, Divita G, Deshayes S. Everything you always wanted to know about CADY-mediated siRNA delivery* (*but afraid to ask). Curr. Pharm. Des. 19(16), 2869-2877 (2013).

173 Koren E, Apte A, Sawant RR, Grunwald J, Torchilin VP. Cell-penetrating TAT peptide in drug delivery systems: proteolytic stability requirements. Drug Deliv. 18(5), 377-384 (2011).

174 Hatakeyama $\mathrm{H}$, Akita $\mathrm{H}$, Harashima $\mathrm{H}$. The polyethyleneglycol dilemma: advantage and disadvantage of PEGylation of liposomes for systemic genes and nucleic acids delivery to tumors. Biol. Pharm. Bull. 36(6), 892-899 (2013).

175 Koren E, Apte A, Jani A, Torchilin VP. Multifunctional PEGylated 2C5-immunoliposomes containing pHsensitive bonds and TAT peptide for enhanced tumor cell internalization and cytotoxicity. J. Control. Release 160(2), 264-273 (2012).

176 Sawant RM, Hurley JP, Salmaso S et al. 'SMART' drug delivery systems: double-targeted pH-responsive pharmaceutical nanocarriers. Bioconjug. Chem. 17(4), 943-949 (2006).

177 Jin E, Zhang B, Sun X et al. Acid-active cell-penetrating peptides for in vivo tumor-targeted drug delivery. J. Am. Chem. Soc. 135(2), 933-940 (2013). 
178 Zhang Q, Tang J, Fu L et al. A pH-responsive a-helical cell penetrating peptide-mediated liposomal delivery system. Biomaterials 34(32), 7980-7993 (2013).

179 Ouahab A, Cheraga N, Onoja V, Shen Y, Tu J. Novel pH-sensitive charge-reversal cell penetrating peptide conjugated PEG-PLA micelles for docetaxel delivery: in vitro study. Int. J. Pharm. 466(1-2), 233-245 (2014).

180 Lee ES, Gao Z, Kim D, Park K, Kwon IC, Bae YH. Super pH-sensitive multifunctional polymeric micelle for tumor pHe specific TAT exposure and multidrug resistance. J. Control. Release 129(3), 228-236 (2008).

181 Jiang T, Zhang Z, Zhang $\mathrm{Y}$ et al. Dual functional liposomes based on $\mathrm{pH}$ responsive cell penetrating peptide and hyaluronic acid for tumor targeted anticancer drug delivery. Biomaterials 33(36), 9246-9258 (2012).

182 Bidwell GL, Raucher D. Cell penetrating elastin-like polypeptides for therapeutic peptide delivery. Adv. Drug Deliv. Rev. 62(15), 1486-1496 (2010).

183 Ryu JS, Raucher D. Elastin-like polypeptide for improved drug delivery for anticancer therapy: preclinical studies and future applications. Expert. Opin. Drug. Deliv. 12(4), 653-667 (2015).

184 Ye J, Shin MC, Liang Q, He H, Yang VC. 15 years of ATTEMPTS: a macromolecular drug delivery system based on the CPP-mediated intracellular drug delivery and antibody targeting. J. Control. Release 205, 58-69 (2014).

185 Morachis JM, Mahmoud EA, Almutairi A. Physical and chemical strategies for therapeutic delivery by using polymeric nanoparticles. Pharmacol. Rev. 64(3), 505-519 (2012).

186 Joglekar M, Trewyn BG. Polymer-based stimuli-responsive nanosystems for biomedical applications. Biotechnol. J. 8(8), 931-945 (2013).

187 Mura S, Nicolas J, Couvreur P. Stimuli-responsive nanocarriers for drug delivery. Nat. Mater. 12(11), 991-1003 (2013).

188 Huang $\mathrm{Y}$, Jiang $\mathrm{Y}$, Wang $\mathrm{H}$ et al. Curb challenges of the 'Trojan Horse' approach: smart strategies in achieving effective yet safe cell-penetrating peptide-based drug delivery. Adv. Drug Deliv. Rev. 65(10), 1299-1315 (2013).

189 Shamay Y, Adar L, Ashkenasy G, David A. Light induced drug delivery into cancer cells. Biomaterials 32(5), 1377-1386 (2011).

190 Yang Y, Xie X, Yang Y, Zhang H, Mei X. Photo-responsive and NGR-mediated multifunctional nanostructured lipid carrier for tumor-specific therapy. J. Pharm. Sci. 104(4), 1328-1339 (2015).

191 Hansen MB, Van Gaal E, Minten I, Storm G, Van Hest JCM, Löwik DWPM. Constrained and UV-activatable cell-penetrating peptides for intracellular delivery of liposomes. J. Control. Release 164(1), 87-94 (2012).

192 Sawant RR, Patel NR, Torchilin VP. Therapeutic delivery using cell-penetrating peptides. Eur. J. Nanomedicine [Internet] 5(3), 141-158 (2013).

193 Deloche C, Lopez-Lazaro L, Mouz S, Perino J, Abadie C, Combette JM. XG-102 administered to healthy male volunteers as a single intravenous infusion: a randomized, double-blind, placebo-controlled, doseescalating study. Pharmacol. Res. Perspect. 2(1), e00020 (2014).

194 Flynn CR, Cheung-Flynn J, Smoke CC et al. Internalization and intracellular trafficking of a PTD-conjugated anti-fibrotic peptide, AZX100, in human dermal keloid fibroblasts. J. Pharm. Sci. 99(7), 3100-3121 (2010).

195 Ponnappan N, Budagavi DP, Yadav BK, Chugh A. Membrane-active peptides from marine organismsantimicrobials, cell-penetrating peptides and Peptide toxins: applications and prospects. Probiotics Antimicrob. Proteins. 7(1), 75-89 (2015). 